\title{
A phylogenomic and molecular signature based approach for characterization of the phylum Spirochaetes and its major clades: proposal for a taxonomic revision of the phylum
}

\section{Radhey S. Gupta *, Sharmeen Mahmood and Mobolaji Adeolu}

Department of Biochemistry and Biomedical Sciences, McMaster University, Hamilton, ON, Canada

\section{Edited by:}

Hiromi Nishida, Toyama Prefectural

University, Japan

\section{Reviewed by:}

Viktoria Shcherbakova, Institute of Biochemistry and Physiology of

Microorganisms, Russian Academy of Sciences, Russia

David L. Bernick, University of California, Santa Cruz, USA

\section{*Correspondence:}

Radhey S. Gupta, Department of Biochemistry and Biomedical Sciences, McMaster University, 1280 Main Street West, Hamilton, ON L8N 3Z5, Canada

e-mail: gupta@mcmaster.ca
The Spirochaetes species cause many important diseases including syphilis and Lyme disease. Except for their containing a distinctive endoflagella, no other molecular or biochemical characteristics are presently known that are specific for either all Spirochaetes or its different families. We report detailed comparative and phylogenomic analyses of protein sequences from Spirochaetes genomes to understand their evolutionary relationships and to identify molecular signatures for this group. These studies have identified 38 conserved signature indels (CSIs) that are specific for either all members of the phylum Spirochaetes or its different main clades. Of these CSIs, a 3 aa insert in the FlgC protein is uniquely shared by all sequenced Spirochaetes providing a molecular marker for this phylum. Seven, six, and five CSIs in different proteins are specific for members of the families Spirochaetaceae, Brachyspiraceae, and Leptospiraceae, respectively. Of the 19 other identified CSIs, 3 are uniquely shared by members of the genera Sphaerochaeta, Spirochaeta, and Treponema, whereas 16 others are specific for the genus Borrelia. A monophyletic grouping of the genera Sphaerochaeta, Spirochaeta, and Treponema distinct from the genus Borrelia is also strongly supported by phylogenetic trees based upon concatenated sequences of 22 conserved proteins. The molecular markers described here provide novel and more definitive means for identification and demarcation of different main groups of Spirochaetes. To accommodate the extensive genetic diversity of the Spirochaetes as revealed by different CSIs and phylogenetic analyses, it is proposed that the four families of this phylum should be elevated to the order level taxonomic ranks (viz. Spirochaetales, Brevinematales ord. nov., Brachyspiriales ord. nov., and Leptospiriales ord. nov.). It is further proposed that the genera Borrelia and Cristispira be transferred to a new family Borreliaceae fam. nov. within the order Spirochaetales.

Keywords: Spirochaetes, Spirochaetes phylogeny and taxonomy, molecular signatures, Spirochaetaceae, Borreliaceae, Brachyspiriales, Leptospiriales, conserved signature indels

\section{INTRODUCTION}

The phylum Spirochaetes consists of a large group of motile bacteria which are widespread in the environment and are highly prevalent disease causing agents (Seshadri et al., 2004; Paster, 2011a). The members of this phylum share a distinguishing morphological feature, the endoflagella, a special class of flagella that folds back into the cell and remains within the periplasm ( $\mathrm{Li}$ et al., 2008). Most spirochetes have one or more of these structures protruding from either pole of the cell, forming an axial filament, which gives rise to the characteristic jerky, corkscrewlike motility of the members of the phylum (Li et al., 2008; Paster, 2011a).Currently, the phylum Spirochaetes consists of 15 genera which are highly divergent in terms of their lifestyle and other characteristics (Euzéby, 2013). They live in marine sediments, deep within soil, commensally in the gut of arthropods, including termites, as well as in vertebrates as obligate parasites. They can also be free-living or host-associated, pathogenic or non-pathogenic, and aerobic or anaerobic (Paster, 2011a). There is also enormous variability in the genome sizes and organization of Spirochaetes species Table 1 . However, despite the diverse characteristics of its members, the phylum Spirochaetes is currently comprised of a single class, Spirochaetia, containing a single order, Spirochaetales, which is made up of four families (viz. Spirochaetaceae, Brachyspiraceae, Leptospiraceae, and Brevinemataceae) (Paster, 2011a; Euzéby, 2013).

There are four clinically important genera of the phylum Spirochaetes whose species are the causative agents of many globally prevalent illnesses, Treponema, Borrelia, Leptospira, and Brachyspira (Bellgard et al., 2009). Of these, Treponema and Borrelia are members of the family Spirochaetaceae, which also includes the genera Clevelandina, Cristispira, Diplocalyx, Hollandina, Pillotina, Spirochaeta, and Sphaerochaeta (Paster, 2011b; Euzéby, 2013). However, the genera Clevelandina, Diplocalyx, Hollandina, and Pillotina have yet to be isolated and 
Table 1 | Genome characteristics of the sequenced members of the phylum Spirochaetes.

\begin{tabular}{|c|c|c|c|c|c|c|}
\hline Strain name & $\begin{array}{l}\text { Accession } \\
\text { number }\end{array}$ & $\begin{array}{l}\text { Size } \\
\text { (Mb) }\end{array}$ & $\begin{array}{l}\text { GC } \\
\%\end{array}$ & Chromosomes & Plasmids & Genome source \\
\hline Borrelia afzelii PKo & NC_017238 & 1.4 & 27.90 & 1 & 17 & Casjens et al., 2011 \\
\hline Borrelia burgdorferi $\mathrm{B} 31^{\top}$ & NC_001318 & 1.52 & 28.18 & 1 & 21 & Zhong and Barbour, 2004 \\
\hline Borrelia crocidurae Achema & NC_017808 & 1.53 & 29.06 & 1 & 39 & Elbir et al., 2012 \\
\hline Borrelia duttonii Ly & NC_011229 & 1.57 & 28.02 & 1 & 16 & Lescot et al., 2008 \\
\hline Borrelia hermsii DAH & NC_010673 & 0.93 & 29.81 & 1 & 2 & Dai et al., 2006 \\
\hline Borrelia recurrentis A1 & NC_011244 & 1.24 & 27.51 & 1 & 7 & Unité des Rickettsies ${ }^{1}$ \\
\hline Borrelia sp. SV1 & NZ_ABJZO00000000 & 1.28 & 28.27 & 1 & 9 & Casjens et al., 2011 \\
\hline Borrelia spielmanii A14S & NZ_ABKB00000000 & 1.25 & 27.69 & - & 8 & Schutzer et al., 2012 \\
\hline Borrelia turicatae 91E135 & NC_008710 & 0.92 & 29.10 & 1 & - & Rocky Mountain Laboratories² \\
\hline Borrelia valaisiana VS116 ${ }^{\top}$ & NZ_ABCY00000000 & 0.35 & 25.83 & - & 11 & Schutzer et al., 2012 \\
\hline Leptonema illini DSM $21528^{\top}$ & NZ_AHKT00000000 & 4.52 & 54.30 & - & - & DOE-JGI $\left.\right|^{3}$ \\
\hline Leptospira biflexa Patoc 1 (Ames) ${ }^{\top}$ & NC_010842 & 3.96 & 38.90 & 2 & 1 & Picardeau et al., 2008 \\
\hline Leptospira borgpetersenii L550 & NC_008509 & 3.93 & 40.20 & 2 & - & Bulach et al., 2006 \\
\hline Leptospira broomii $5399^{\top}$ & NZ_AHMO00000000 & 4.49 & 42.90 & - & - & $J_{C V}^{4}$ \\
\hline Leptospira inadai $10^{\top}$ & NZ_AHMM00000000 & 4.57 & 44.50 & - & - & $\mathrm{JCV}^{4}$ \\
\hline Leptospira interrogans $\mathrm{RGA}^{\top}$ & NZ_AOVR00000000 & 4.6 & 35.00 & 2 & - & $\mathrm{JCV}^{4}$ \\
\hline Leptospira kirschneri $3522 \mathrm{C}^{\top}$ & NZ_AHMN00000000 & 4.4 & 35.90 & - & - & $\mathrm{JCV}^{4}$ \\
\hline Leptospira kmetyi Bejo-lso9 ${ }^{\top}$ & NZ_AHMP00000000 & 4.48 & 44.70 & - & - & $\mathrm{JCV}^{4}$ \\
\hline Leptospira licerasiae VAR $010^{\top}$ & NZ_AHOO00000000 & 4.21 & 35.90 & - & - & $\mathrm{JCV}^{4}$ \\
\hline Leptospira meyeri Went 5 & NZ_AKXE00000000 & 4.19 & 38.00 & - & - & $\mathrm{JCV}^{4}$ \\
\hline Leptospira santarosai LT $821^{\top}$ & NZ_ADOR00000000 & 3.88 & 41.80 & - & - & Chou et al., 2012 \\
\hline Spirochaeta thermophila DSM $6578^{\top}$ & NC_017583 & 2.56 & 60.90 & 1 & - & DOE-JGI $\left.\right|^{3}$ \\
\hline Treponema azotonutricium ZAS-9 ${ }^{\top}$ & NC_015577 & 3.86 & 49.80 & 1 & - & $\mathrm{JCV}^{4}$ \\
\hline Treponema brennaborense DSM $12168^{\top}$ & NC_015500 & 3.06 & 51.50 & 1 & - & DOE-JGI ${ }^{3}$ \\
\hline Treponema caldaria DSM $7334^{\top}$ & NC_015732 & 3.24 & 45.60 & 1 & - & Abt et al., 2013 \\
\hline Treponema denticola ATCC $35405^{\top}$ & NC_002967 & 2.84 & 37.90 & 1 & 1 & Seshadri et al., 2004 \\
\hline Treponema pallidum Nichols & NC_000919 & 1.14 & 52.80 & 1 & - & Fraser et al., 1997 \\
\hline Treponema paraluiscuniculi Cuniculi A & NC_015714 & 1.13 & 52.70 & - & - & Smajs et al., 2011 \\
\hline Treponema phagedenis $\mathrm{F} 0421$ & NZ_AEFH00000000 & 2.83 & 40.10 & - & - & WUGSC 5 \\
\hline Treponema primitia ZAS-2 $2^{\top}$ & NC_015578 & 4.06 & 50.80 & 1 & - & $\mathrm{JCV}^{4}$ \\
\hline Treponema saccharophilum DSM $2985^{\top}$ & NZ_AGRW00000000 & 3.45 & 53.20 & - & - & DOE-JGI $\left.\right|^{3}$ \\
\hline Treponema sp. JC4 & NZ_AJGU00000000 & 3.03 & 40.30 & - & - & $\mathrm{CSIRO}^{6}$ \\
\hline Treponema succinifaciens DSM $2489^{\top}$ & NC_015385 & 2.9 & 39.17 & 1 & 1 & Han et al., 2011 \\
\hline Treponema vincentii ATCC 35580 & NZ_ACYH00000000 & 2.51 & 45.70 & - & - & $\mathrm{JCV}^{4}$ \\
\hline Turneriella parva DSM $21527^{\top}$ & NC_018020 & 4.41 & 53.60 & 1 & 1 & DOE-JGI $\left.\right|^{3}$ \\
\hline
\end{tabular}

Genomic information was collected from: http://www.ncbi.nlm.nih.gov/genomes/

${ }^{1}$ Unité des Rickettsies: Genome sequenced by Unité des Rickettsies at Center National de Référence.

${ }^{2}$ Rocky Mountain Laboratories: Genome sequenced by the Laboratory of Human Bacterial Pathogenesis at Rocky Mountain Laboratories.

${ }^{3}$ DOE-JGI: Genome sequenced by the United States Department of Energy Joint Genome Institute.

${ }^{4}$ JCV: Genome sequenced by the J. Craig Venter Institute.

${ }^{5}$ WUGSC: Genome sequenced by the Washington University Genome Sequencing Center.

${ }^{6}$ CSIRO: Genome sequenced by the Commonwealth Scientific and Industrial Research Organization.

TType strain. 
grown in pure or mixed culture and their phylogeny is based largely on analyses of morphological characteristics (Bermudes et al., 1988). Treponema pallidum subspecies pallidum is the causative agent of syphilis, a sexually transmitted disease which affects at least 25 million adults worldwide (Gerbase et al., 1998). Other members of the genus Treponema are responsible for diseases such bejel, yaws, and pinta and play important role in periodontal diseases (Ellen and Galimanas, 2005; Visser and Ellen, 2011; Smajs et al., 2012). Members of the genus Borrelia, namely Borrelia burgdorferis and Borrelia recurrentis, are important human pathogens that cause Lyme disease and relapsing fever, respectively (Dworkin et al., 2008; Nau et al., 2009; Cutler, 2010). Leptospira and Brachyspira, are members of the families Leptospiraceae and Brachyspiraceae, and causative agents of the diseases leptospirosis and intestinal spirochaetosis, respectively (Adler and de la Peña Moctezuma, 2010; Anthony et al., 2013; Euzéby, 2013).

Despite the importance of species of the phylum Spirochaetes in causing many important human diseases, the evolutionary relationship of species within this phylum remains poorly understood and no distinguishing molecular features are known that are specific for all members of the different families (Olsen et al., 2000; Paster and Dewhirst, 2000; Paster, 2011a). The availability of genome sequences provides a valuable resource to identify/discover novel molecular markers that are helpful in these regards and to gain insights into their evolutionary relationships. Genomes from 48 species covering the three main families of the phylum Spirochaetes are now available in the NCBI database (Table 1) (NCBI, 2013). The availability of genome sequences allows for the use of comparative genomic approaches to identify molecular markers that are specific for different bacterial taxa at various taxonomic levels. Using genomic sequences, one useful approach pioneered by our lab involves the discovery of Conserved Signature insertions/deletions (i.e., Indels) or CSIs present in protein sequences that are specific for different groups of organisms. Due to the specificity of these CSIs for particular groups/taxa of species, they provide valuable molecular markers of common evolutionary descent (i.e., synapomorphies) for identification and demarcation of different phylogenetic/taxonomic clades of organisms in molecular terms. Additionally, based upon the presence or absence of these CSIs in outgroup species, it is possible to infer whether the observed genetic change is an insert or a deletion and a rooted phylogenetic relationship among different groups can be derived (Baldauf and Palmer, 1993; Gupta, 1998; Griffiths and Gupta, 2004; Gao and Gupta, 2012a).

In this work, we report the results of comparative analyses on protein sequences for the phylum Spirochaetes to identify molecular markers (CSIs) that are specific for the species from the phylum and its subgroups, or those that provide information regarding interrelationships among them. These studies have led to identification of 38 CSIs providing novel molecular markers for the species from the phylum and clarifying their evolutionary relationships. Additionally, we have also constructed a phylogenetic tree for all genome sequenced members of the phylum Spirochaetes based upon concatenated sequences for 22 conserved proteins. The inferences from different identified CSIs are strongly supported by the branching pattern of species in the phylogenetic tree indicating that the identified CSIs provide reliable molecular markers for the indicated groups of Spirochaetes.

\section{METHODS \\ PHYLOGENETIC SEOUENCE ANALYSIS}

Phylogenetic analysis was performed on a concatenated sequence alignment of 22 highly conserved proteins (viz. UvrD, GyrA, GyrB, RpoB, RpoC, EF-G, EF-Tu, RecA, ArgRS, IleRS, ThrRS, TrpRS, SecY, DnaK, and ribosomal proteins L2, L5, S2, S3, and S9) which have been widely used for phylogenetic analysis (Harris et al., 2003; Gao and Gupta, 2012a). Sequences for these proteins were obtained from the NCBI database for representative strains of all the sequenced Spirochaetes species (Table 1) and Thermosynechococcus elongatus and Nostoc flagelliforme which were used to root the tree. Multiple sequence alignments for these proteins were created using Clustal_X 1.83 (Jeanmougin et al., 1998) and concatenated into a single alignment file. Poorly aligned regions from this alignment file were removed using Gblocks $0.91 \mathrm{~b}$ (Castresana, 2000). The resulting alignment, which contained 7411 aligned amino acids, was used for phylogenetic analysis. The maximum likelihood (ML) and neighbor joining $(\mathrm{NJ})$ trees based on 100 bootstrap replicates of this alignment were constructed using MEGA 5.1 (Tamura et al., 2011) employing the Whelan and Goldman (Whelan and Goldman, 2001) and Jones-Taylor-Thornton (Jones et al., 1992) substitution models, respectively.

A 16S rRNA gene sequence tree was also created for 107 sequences that included representative species for all $11 \mathrm{cul}$ tured Spirochaetes genera. 16S rRNA gene sequences larger than $1200 \mathrm{bp}$ were obtained for all type species classified under the phylum Spirochaetes in release 114 of the SILVA database (Quast et al., 2013). Information for these sequences is provided in Supplemental Table 1. A ML tree based on these sequences was created using 100 bootstrap replicates of the 16S rRNA sequence alignments in MEGA 5.1 (Tamura et al., 2011) employing the General Time-Reversible (Tavaré, 1986) substitution model.

\section{IDENTIFICATION OF MOLECULAR MARKERS (CSIs)}

To identify CSIs that are commonly shared by different groups of Spirochaetes, BLASTp searches (Altschul et al., 1997) were performed on each protein in the genome of Treponema pallidum subspecies pallidum strain Nichols. These searches were performed using the default BLAST parameters against all available sequences in the GenBank non-redundant database. For those proteins for whom high scoring homologs $\left(E\right.$-values $\left.<1 \mathrm{e}^{-20}\right)$ were present in other species from the phylum Spirochaetes and some other bacterial groups multiple sequence alignments were created using the Clustal_X 1.83 program (Jeanmougin et al., 1998). These alignments were visually inspected for the presence of insertions or deletions that were flanked on both sides by at least 4-5 conserved amino acid residues in the neighboring 30-40 amino acids. Indels that were not flanked by conserved regions were not further considered, as they do not provide useful molecular markers (Gupta, 1998; Gao and Gupta, 2012a; Adeolu and Gupta, 2013). The specificity of potentially useful indels for members of the Spirochaetes was further evaluated by carrying out detailed Blastp searches on short sequence segments containing 
the indel and the flanking conserved regions (60-100 amino acids long). To ensure that the identified signatures are only present in the Spirochaetes homologs, a minimum of 250 blast hits with the highest similarity to the query sequence were examined for the presence or absence of these CSIs. In this work, we report the results of only those CSIs that are specific for different groups of Spirochaetes and where similar CSIs were not observed in any other bacteria in the top 250 blast hits. The sequence alignment files presented here contain sequence information for all sequenced genera within Spirochaetes. However, due to size restraints, different strains and/or species of the sequenced genera are not shown as they all exhibited similar patterns.

\section{RESULTS}

\section{GENOMIC CHARACTERISTICS OF THE SEOUENCED SPIROCHAETES}

There are currently 48 genome sequenced species of Spirochaetes. Table 1 lists some characteristics of representative strains for all Spirochaetes species that have been completely sequenced. The genome sizes of these species of Spirochaetes showed a large amount of variation, ranging from 0.92 to $4.7 \mathrm{Mb}$ in length. The $\mathrm{G}+\mathrm{C}$ content of these species also showed a large amount of variation, ranging from 25.8 to $60.9 \%$. The members of the phylum Spirochaetes also exhibited a large amount of variation in genome structure. The genome structure of members of genus Borrelia is one of the most unique among prokaryotes (Chaconas, 2005; Chaconas and Kobryn, 2010). The Borrelia genome consists of 6-24 DNA segments, including a linear chromosome about $900 \mathrm{~kb}$ in length which is accompanied by multiple essential linear and circular plasmids ranging from 5 to $220 \mathrm{~kb}$ in length (Chaconas and Kobryn, 2010). Linear chromosomes and plasmids terminated by covalently closed hairpin telomers are particularly uncommon genomic features among prokaryotes and are only found in the genomes of the Borrelia species and the species Agrobacterium tumefaciens (Goodner et al., 2001; Kobryn, 2007; Chaconas and Kobryn, 2010). Members of the genus Leptospira also have an unusual genome structure consisting of two circular chromosomes, a big chromosome about 3.6-4.2 Mb in length and a smaller chromosome about $300 \mathrm{~kb}$ in length (Ren et al., 2003; Picardeau et al., 2008).

\section{PHYLOGENETIC ANALYSES OF THE SEQUENCED SPIROCHAETES}

The branching order of species within the phylum Spirochaetes has primarily been determined using $16 \mathrm{~S}$ rRNA sequence based phylogenetic trees (Paster and Dewhirst, 2000; Paster, 2011a). In these trees, the four families with the phylum branch into distinct monophyletic clades separated by long branches. However, the interrelationships of members of the family Spirochaetaceae are not reliably resolved (Paster, 2011b) (Figure 2). Phylogenetic trees derived from large numbers of conserved genes/proteins provide greater resolving power than those based on any single gene or protein (Rokas et al., 2003; Ciccarelli et al., 2006; Wu et al., 2009; Gao and Gupta, 2012a). In this study, we have constructed phylogenetic trees of the genome sequenced members of the phylum Spirochaetes listed in Table 1 using 22 conserved housekeeping and ribosomal proteins. The trees were constructed using both the NJ and ML methodologies and branching patterns generated by both methodologies were highly similar (Figure 1).
In the concatenated protein trees, which are rooted using the species T. elongatus and $N$. flagelliforme, the members of the three sequenced families of Spirochaetes (viz. Spirochaetaceae, Brachyspiraceae, and Leptospiraceae) formed three distinct monophyletic clades (Figure 1). Additionally, the branching order of members of the family Spirochaetaceae is well-resolved in the concatenated protein trees. Within the Spirochaetaceae clade, the genera Treponema, Spirochaeta, and Sphaerochaeta formed a well-supported monophyletic clade separated from the members of the genus Borrelia by a long branch. The Treponema, Spirochaeta, and Sphaerochaeta clade exhibited a large amount of diversity and consisted of a number of strongly supported subclades. Members of each of the sequenced genera within Spirochaetes formed monophyletic clusters with the exception of the genus Spirochaeta, where Spirochaeta smaragdinae branched with the genus Sphaerochaeta. Another Spirochaeta species, S. caldaria, which branched within the Treponema has recently been reclassified as Treponema caldaria (Abt et al., 2013). The remaining Spirochaeta (viz. S. thermophila and S. africana) branched deeply within the Treponema, Spirochaeta, and Sphaerochaeta clade (Figure 1). The monophyletic clade containing all the members of the genus Borrelia consisted of two highly distinct subclades, one containing Borrelia burgdorferi, and related species of Borrelia and the other containing Borrelia recurrentis related species.

The 16S rRNA tree shown in Figure 2 includes all of the members included in the concatenated protein tree as well as other cultured members of the phylum Spirochaetes which have yet to be genome sequenced. The branching patterns in the 16S rRNA phylogenetic tree were similar to those observed in the concatenated protein tree; all families within the phylum branched distinctly. Within the cluster consisting of members of the family Spirochaetaceae the genera Treponema, Sphaerochaeta, and most members of the genus Spirochaeta formed a monophyletic clade. The genera Borrelia and Cristispira also formed a well-supported monophyletic clade that was distinct from the genera Treponema, Spirochaeta, and Sphaerochaeta within the Spirochaetaceae clade. The different sequenced members of the genus Borrelia also formed two distinct clusters in the 16S rRNA tree (Figure 2).

\section{CSI SPECIFIC FOR THE PHYLUM SPIROCHAETES}

CSIs that are restricted to a group of related species are a novel class of molecular marker with high utility for evolutionary studies (Gupta, 1998; Rokas et al., 2003; Gupta, 2009; Gao and Gupta, 2012a). The co-occurrence of multiple CSIs in different species may be due to shared evolutionary history, convergent evolution, lateral gene transfer. However, the unique shared presence of multiple CSIs in a diverse range by a related group of species is most parsimoniously explained by the occurrence of the rare genetic changes that resulted in these CSIs in a common ancestor of the group, followed by vertical transmission of these CSIs to various descendant species (Gupta, 1998; Rokas and Holland, 2000; Gogarten et al., 2002; Gupta and Griffiths, 2002; Gao and Gupta, 2012a). Hence, these CSIs represent molecular synapomorphies of common evolutionary descent and they provide useful markers for identifying different groups of organisms in molecular terms and for understanding their interrelationships independently of 


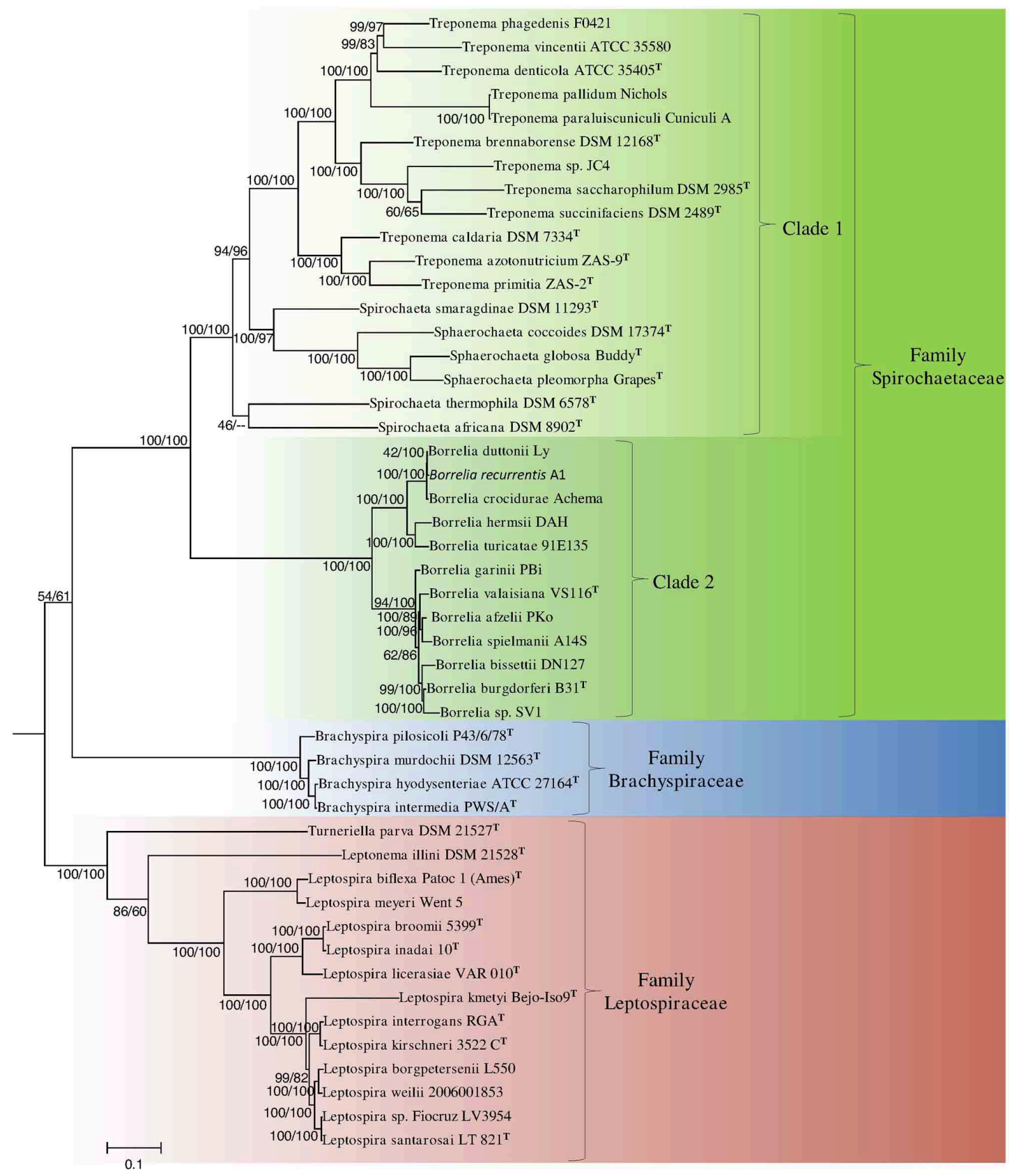

FIGURE 1 | A phylogenetic tree of genome sequenced members of the phylum Spirochaetes based on the concatenated amino acid sequences of 22 conserved proteins. The tree shown is a maximum-likelihood (ML) distance tree. Bootstrap values are shown at branch nodes for both maximum-likelihood and neighbor-joining tree construction methods as ML/NJ. The different sequenced families and two main clades of the family Spirochaetaceae supported by the tree are marked. The letter ${ }^{\top}$ refers to the type strain of the species. phylogenetic trees (Gupta, 1998; Gupta and Griffiths, 2002; Gao and Gupta, 2012a,b). The CSI-based approach has recently been used to propose important taxonomic changes for a number of groups of bacteria (viz. Chloroflexi, Coriobacateriia, Neisseriales, and Bacillus) at different taxonomic ranks (Gupta et al., 2012, 2013; Adeolu and Gupta, 2013; Bhandari et al., 2013). In the present work, we have completed comprehensive genomic analyses to identify CSIs that are primarily restricted to the phylum 


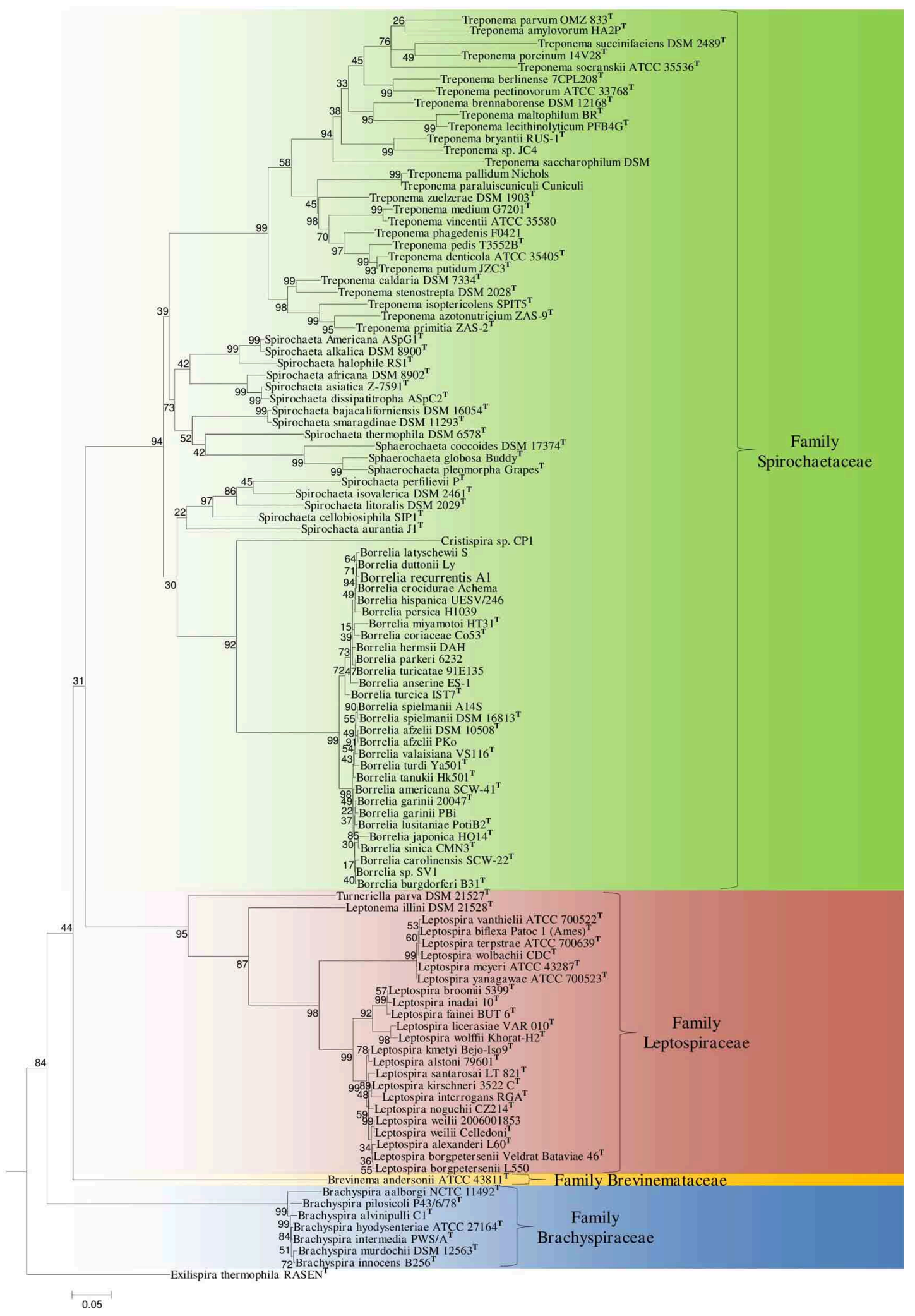

FIGURE 2 | A ML tree based on the 16S rRNA gene sequences of representative species from cultured genera within the phylum

Spirochaetes. Bootstrap values are shown at branch nodes. The different families of the phylum Spirochaetes are marked. The letter ${ }^{\top}$ refers to the type strain of the species. The accession numbers of the 16S rRNA gene sequences used in this analysis are provided in Supplemental Table 1. 
Spirochaetes or its subgroups. Information regarding the species specificities of these CSIs and their evolutionary significances are discussed below.

Our analyses have identified 38 CSIs in diverse and important proteins that are specific for members of the Spirochaetes. One CSI has been identified that is specifically found in all of the sequenced members of the phylum Spirochaetes and not found in homologous proteins from any other bacterial species (in the top 250 Blast hits) (Figure 3). This CSI consists of a 3 amino acid (aa) insertion located in the flagellar basal-body rod protein FlgC, a component of the basal body which comprises a large portion of the flagella (Macnab, 2003). This CSI represents a unique molecular characteristic of the phylum Spirochaetes and may be related to

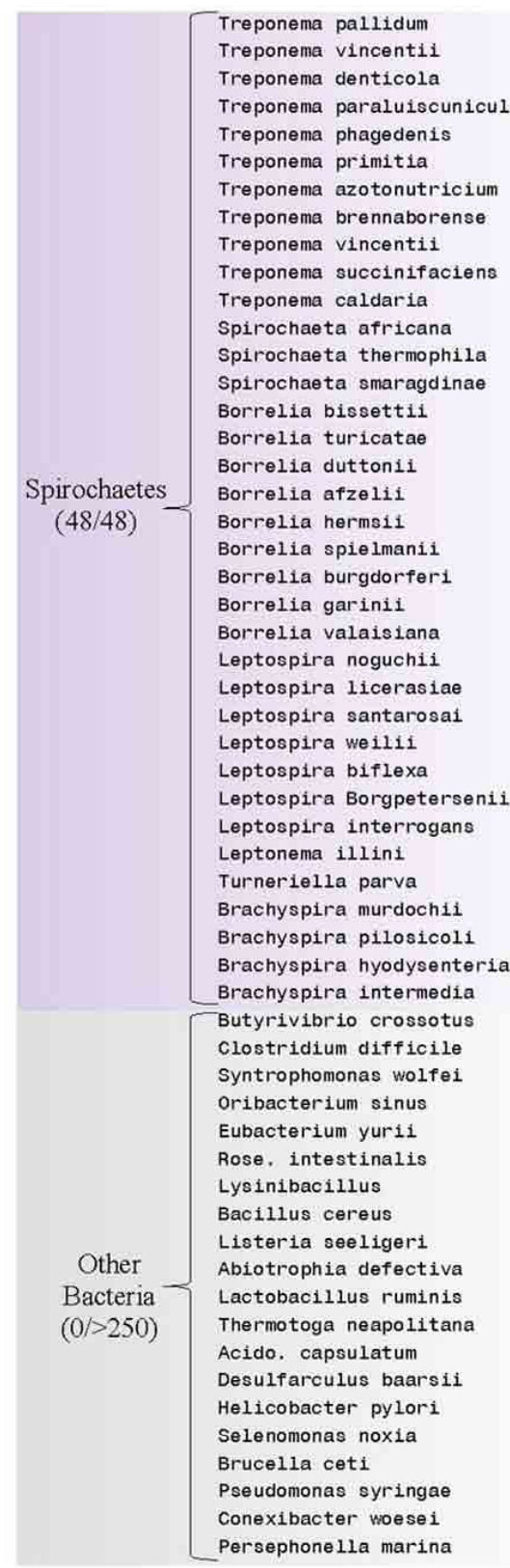

FIGURE 3 |A partial sequence alignment of the flagellar basal-body rod protein FlgC, showing a CSI (boxed) that is uniquely present in all members of the phylum Spirochaetes. Sequence information for only a limited number of species from the Spirochaetes and other bacteria is shown here, but unless otherwise indicated similar CSIs were detected in all members of the indicated

\begin{tabular}{|c|c|c|c|}
\hline \multirow[b]{2}{*}{291059787} & 92 & & \\
\hline & YDPTHPDA & ILS & GPKAGYVEYPNVDIVTEMVD \\
\hline 257457889 & $-E-D--H-$ & $-v-$ & 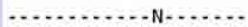 \\
\hline 2526722 & ....... K- & LKY & 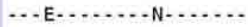 \\
\hline 387063 & n........ & $\cdots$ & (.). \\
\hline 20535379 & $\ldots N \cdots$ & $-\mathrm{K}-$ & $\because N-\ldots, \ldots, n$ \\
\hline 333997909 & .......... & $-K A$ & $\cdots Q-\ldots, M-\cdots, V \cdots$ \\
\hline 333994363 & n....... & $-T T$ & $\because R Q-\cdots M-\ldots \ldots \ldots$ \\
\hline 32297607 & $\ldots s \ldots$ & $-Q-$ & $\cdots N-\ldots \ldots+n-n-N$ \\
\hline 257457889 & $-E-D-C H$ - & $-V-$ & . n \\
\hline 328947992 & $\ldots s \ldots$ & $-Q$ - & $\cdots N K-\cdots \cdots+N-N-\cdots N$ \\
\hline 339500288 & n........ & $-K T$ & $\cdots R \cdots \cdots M-\cdots N-\cdots \cdots$ \\
\hline 73485215 & $\ldots \ldots$ & $-R-$ & $\cdots R E-\cdots M-\cdots N-E-\cdots$ \\
\hline 307718596 & n....... & $-\mathrm{k}$ - & $\because$ LK $\cdots \cdots \cdots,-N-N-\cdots$ \\
\hline 302338075 & ......... & -QT & $\cdots \mathrm{K}-\cdots \mathrm{M}-\cdots \mathrm{N}-\mathrm{E}-\cdots$ \\
\hline 343127611 & ........s & $-G-$ & -DRK $\cdots$ L $\cdots$ NL-E $\cdots$ \\
\hline 19953092 & $\ldots \ldots$ & $-\mathrm{K}-$ & -ERK-...F...NA-E-... \\
\hline 203284214 & $\ldots \ldots$ & $-k$ - & -ELK-...F-..NV - E - ... \\
\hline 111115118 & ......s s & $-\mathrm{s}$. & $-D \cdot K \cdots-\cdots \cdots N L-E \cdots$ \\
\hline 187918167 & n....... & $-R$ - & -ELK- $\cdots F-\cdots N A-E-\cdots$ \\
\hline 224534284 & .......s & -5 - & 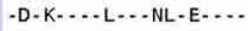 \\
\hline 1448943 & $\cdots A \cdots S$ & $-s$. & 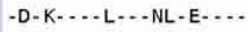 \\
\hline 51598553 & n.....s & $-\mathrm{SF}$ & $-D-K \cdots L-\cdots N L-E-\cdots$ \\
\hline 224531802 & a.....s s & $-S F$ & $-D-K \cdots-L \cdots N L-E-\cdots$ \\
\hline 359724699 & $\ldots \ldots$ & $-Q I$ & $\cdots \mathrm{K}-\cdots \mathrm{M}-\cdots \mathrm{N}-\cdots \cdot \mathrm{T}$. \\
\hline 359687476 & $\ldots \ldots$ & $-Q I$ & $\cdots \mathrm{K} \cdot \cdots \mathrm{M}-\cdots \mathrm{N} \cdots \cdot \mathrm{T}$ - \\
\hline 359684672 & n........ & $-Q I$ & $\because N K-L-M-\cdots N-\cdots$ T. \\
\hline 359729323 & $F \ldots E \ldots$ & $-G R$ & -S-K- - - F - I ILEE-L \\
\hline 183220163 & n....... & $-Q T$ & $\cdots$ K $\cdots$ L $\cdots$ IN $\cdots$. T. \\
\hline 116327145 & .......... & $-Q I$ & $\cdots$ K...M-M \\
\hline 294827625 & .......s s & $-Q I$ & $\cdots \mathrm{K} \cdots \mathrm{M} \cdots \mathrm{N} \cdots \cdots$ T- \\
\hline 373872765 & $F=G-\ldots$ & $-K I$ & $\cdots Q-\cdots M-\cdots N \cdots E-T-$ \\
\hline 392405560 & F.-S.... & VKV & 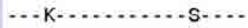 \\
\hline 296127542 & $\ldots s \ldots$ & $-K Y$ & $-E-\ldots . M-M-N P \ldots$ \\
\hline 300870979 & $\ldots s \ldots$ & $-K Y$ & $-E \cdots-M--N P \ldots$ \\
\hline 225619783 & $\ldots s \ldots$ & $-K Y$ & $-E-\ldots . M-M N P \ldots$ \\
\hline 384208491 & $\ldots s \ldots$ & $-K Y$ & $-E \cdot \ldots \cdot M-N-N P \ldots$ \\
\hline 260438810 & ...s.... & & DEN $\cdots$ K - - $-\mathrm{N}--\mathrm{N} \cdots \mathrm{T}-$ \\
\hline 255099413 & $\ldots s \ldots$ & & KPN $\cdots \ldots . . . N-L V \cdots T$. \\
\hline 14566383 & -.S.-E. & & DNE $\cdots-N \cdots N--E-I N$ \\
\hline 227873538 & $-N-N-\cdots$ & & DAQ - - N $\cdots . .$. LK-T .. \\
\hline 306820111 & $\ldots G \ldots$ & & DEN . . KM $\ldots$ ELI $\ldots \ldots$ \\
\hline 240145509 & $\ldots s \ldots . .$. & & DEN $\cdots T \cdots N T \cdots$ TN \\
\hline 299534789 & $\ldots \ldots$ & & NAD . - NM .... PLK .... \\
\hline 218230982 & $\ldots . . . .$. & & $N-E \cdots R \cdots I-V T A \cdots T N$ \\
\hline 289433989 & $\cdots \cdots \mathrm{N}-$ & & NE $\cdots N-A \cdots M T A \cdots T N$ \\
\hline 229826300 & $\ldots s \ldots$ & & NED $\cdots T \cdot \ldots$ NT - Q $\cdots T$ T- \\
\hline 227528457 & $\cdots N \cdots$ & & DAN $\ldots$. M $\ldots$ NIAAD $\cdots$ \\
\hline 222100200 & $\ldots . . .1$ & & DEN - - RM- - $-\mathrm{N}-\mathrm{R}-\ldots$ \\
\hline 225871925 & ...s.... & & D-Q $\cdots$ S $-E I N P \ldots$. \\
\hline 302342345 & $\mathrm{H}, \mathrm{S} \ldots .$. & & DAD $\cdots L \cdots-V \cdots N$ \\
\hline 308064340 & $\ldots s \ldots$ & & $N A Q \cdots A \cdots N A-V-A-$ \\
\hline 292669734 & $-E-G-\ldots$ & & 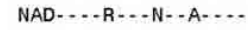 \\
\hline 256158120 & $\cdots S-A-$ & & DAR $\cdots K \cdots$ NM-V- \\
\hline 28869138 & $-E-N--S-$ & & $D-D \cdots Y \cdots N$ N $-E-A-A$ \\
\hline 284041507 & $\ldots G \ldots$ & & DPR $\ldots$ - AM $\ldots$ NP. . \\
\hline 25850273 & F..S... & & DQN $\ldots A \cdots \cdots$ PLF \\
\hline
\end{tabular}

group and not detected in any other bacterial species in the top 250 Blastp hits. The dashes (-) in the alignments indicate identity with the residue in the top sequence. GenBank identification (GI) numbers for each sequence are indicated in the second column. Sequence homologs for this protein were not identified from members of the genus Sphaerochaeta. 
the characteristic flagellar morphology shared by members of the phylum.

\section{CSIS THAT ARE SPECIFIC FOR DIFFERENT FAMILIES OF SPIROCHAETES}

Many of the CSIs identified by our analyses are specific for the different sequenced families within the phylum Spirochaetes (viz. Spirochaetaceae, Brachyspiraceae, and Leptospiraceae) allowing us to demarcate these families in clear molecular terms.
Seven of the CSIs identified by our analyses are specific for the family Spirochaetaceae. One example of a CSI that is specific for the species from the family Spirochaetaceae is a 15 aa insertion in a highly conserved region of the protein phosphoribosylpyrophosphate synthetase, which is uniquely found in all members of the family Spirochaetaceae but not in any other sequenced bacterial groups (Figure 4). Sequence information for 6 other CSIs in diverse proteins (viz. Alanyl-tRNA synthetase,

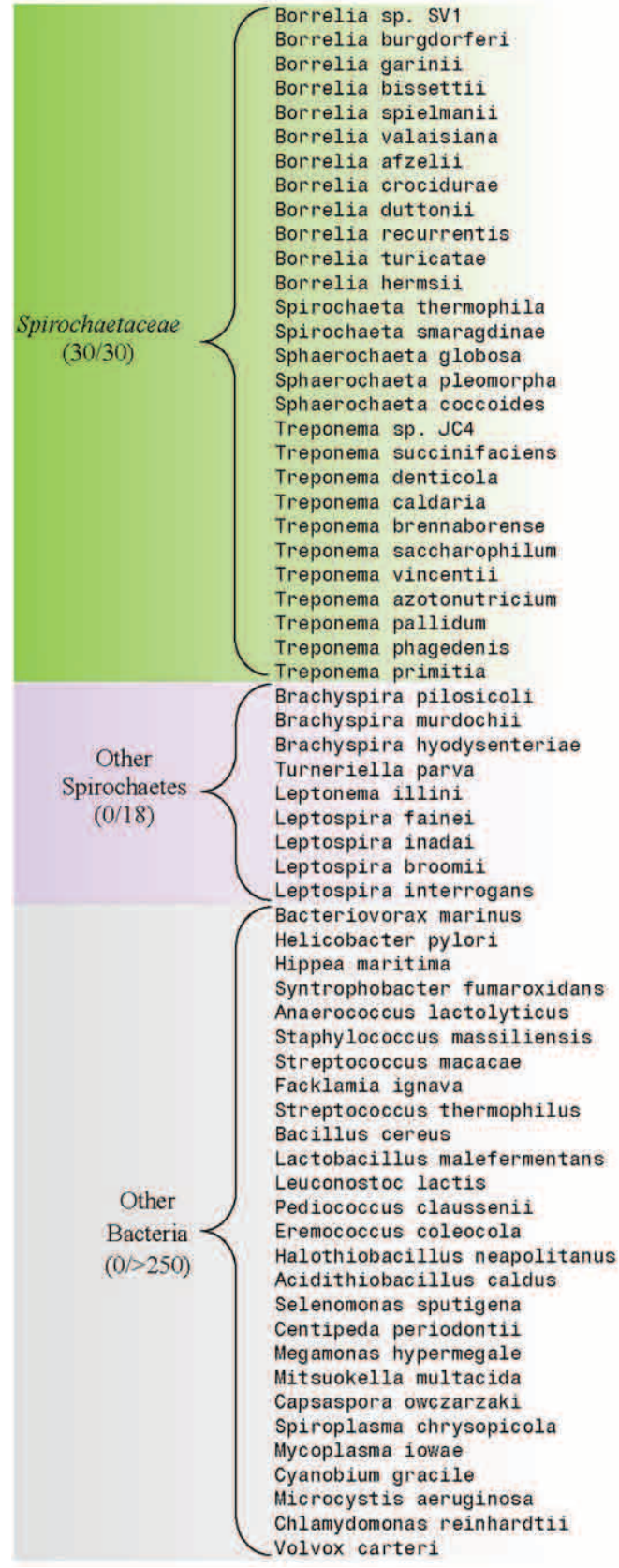

FIGURE 4 | A partial sequence alignment of the protein alanyl-tRNA synthetase showing a two amino acid insertion (boxed) identified in homologs from the family Spirochaetaceae, but not found in the
97

496158147

218249888

51598795

343127845

493478988

492960169

384207032

386859775

203284450

203287984

119953329

187918407

307719014

302337090

325971852

374317254

330837008

496394911

488752940

339498915

332297752

488791143

493197584

333994388

15639286

488785632

333996912

404476574

296125819

225216214

392404244

488860053

514358906

498101250

498256941

463284931

374290019

385226974

327399268

116748649

490965715

496848324

489169291

493751806

386087062

446029563

49830594

497688032

377809552

493462576

261855768

491008878

330839472

493349495

479205918

492431171

470296469

507379176

490124334

427701574

488876880

159472214

302842949
143

MAYVDA NAYEVEINSSEKII MTVNDHIMNLUTTIDA

(l)

(n.............

(n.............

n...R.........

(n..............

A...S - T.P.TV-NN-EVV

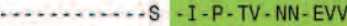

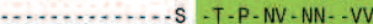

C............ S - T-P-NV-NN- - VV

L-SSV-D-EVY …..E - R-PQRFSDGKEYT

.

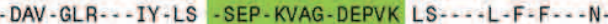

-DAV-GLRV .... Y LS -MEP-KVAG-DEP-H LS ....L-F-L...N-

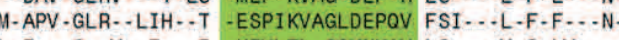

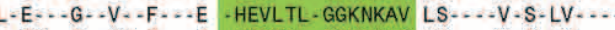

-DC.-G.-VYY-F...E - HEKIAL-DGKNVLS LS....-V-S-LV...

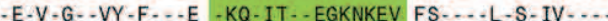

-ES - G .........E - HHPLPF- DGKN-KV LS .......... LV.V -

-NEC - G -.V - - F -..E - HQPIKL-GGKNLQV LS ....... SMLV -...

-ECV-G...Y.F...E - HEPIKM-GGKNEVV FS....V.T. LV...

-EC.-G-NV - - F -...E - - H-PLSV-EGKNOHV FS .... L-SM-V....

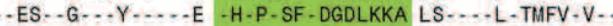

-NEC - - G - V - - F - . - E - HOP-LV-NGKSKKI FS -...V-M-IV ...

-NEC - G - - V - - F - . E - HOVLTV-OGKNKOR FS ....L-S-IV ....

-ES - - G - MY -F ....E - HHPLNF-NGSLSKA LSI ...L-SIFV - V -

EE-A …TY-I-PTG R PSS-ESW-E-FCV..

EE - V ....TY-I.PTG R PSSSENW-E-YCI ...

-EE-V....TYVI-PTG R PSSSESW-E-YCI ...

SENV-GS-V-VI-STS

NEN-.G..V ....PTS APA - -NL-E-LLI ...

-EENV-GR...LI-STS APA -..L-E-LLIM-

-EENV-GR -..LII-STS APA -..L-E-LLIM-

DENV-GR ...LI-STS APA-..L-E-LLIM-

APA ...L-E-ILIM.

-E-NV-GA-V-VI-STS SP....V-E-LIM..

-SESV-G....... PTC -P...NL-E-LVMV-

-DESV-GA-V-LI-SLS SP...N--E-LV-L.

-GENV-GA...V -.SG - QP...L-E-LVM-..

NES - - G ..V ....PTS NPT. - NL-E-LIM ..

-EES - - GC-V - I-I-PTS NP ....L-E-LIM. .

-EESV-GS ..Y-I-STS NP.... LWE-LIMV-

NP.-E-L-E-LIA ...

NP....LWE-LIM...

FP..E...E-LIM...

NP.-SML-E- - IM-..

AP...NL-E-LIM...

DPI - S SL-E-LIM-.

NP...NL-E..IC...

DPT - - N - - E - V VMV -

APT...L-E-L.L...

QP...NL-E.LIMT.

FP...NL-E-LILT.

QP...NL-E.LVMA.

YP...NL-E-LIMA-

GD...NL-E-LIM-N-

NP..ENL-E-LIA ...

NP...NL-E-LIG...

AP....L.E.-IMV -

NP....L-E.LIM...

PP....L-E-LI ...

PP....L.E.LIM... 
phosphoribosylpyrophosphate synthetase, preprotein translocase SecY, peptide chain release factor 2, DNA mismatch repair protein MutS, and DNA mismatch repair protein MutL) that are also specifically present in members of the family Spirochaetaceae is presented in Supplementary Figures 1-6 and some of their characteristics are summarized in Table 2.

Our analyses have also identified 6 CSIs in diverse proteins that are specifically found in members of the family Brachyspiraceae and absent in all other bacterial groups. One of these Brachyspiraceae-specific CSIs, a 1 aa insertion, is present in the flagellar hook-associated protein $\mathrm{FlgK}$, a protein involved in flagellar hook morphogenesis (Figure 5A) (Homma et al., 1990). Another Brachyspiraceae-specific CSI, a 1 aa insertion, is found in a highly conserved region of DNA polymerase I (Figure 5B). These proteins represent highly conserved and essential components of members of the family Brachyspiraceae which contain conserved molecular changes not found in any other sequenced bacterial group. Sequence information for 4 other CSIs in three other proteins (viz. valyl-tRNA synthetase, ATP-dependent protease La, and glutamyl-tRNA amidotransferase subunit B) that are also specifically present in members of the family Brachyspiraceae is presented in Supplemental Figures $7-10$ and some of their characteristics are summarized in Table 3.

We have also identified 5 CSIs that are uniquely present in members of the family Leptospiraceae. Two examples of such CSIs are shown in Figure 6. The first of these CSIs, an 8 aa insertion in the 50S ribosomal protein L14, is shown in Figure 6A, and the other CSI, a 4 aa insert in alanyl-tRNA synthetase, is shown in Figure 6B. Both of these CSIs are found in members of the the family Leptospiraceae and absent in every other sequenced bacterial group. Sequence information for 4 other CSIs in diverse proteins (viz. 30S Ribosomal protein S2, flagellar basal-body rod protein FlgG, and flagellar filament core protein FlaB) that are also specifically present in members of the family Leptospiraceae is presented in Supplemental Figures 11-14 and some of their characteristics are summarized in Table 4.

\section{CSIs DISTINGUISHING TWO CLADES WITHIN THE FAMILY Spirochaetaceae}

In addition to the numerous CSIs identified in our analyses for the sequenced families within the phylum Spirochaetes, we have also identified a number of CSIs that elucidate the relationship of the genera within the family Spirochaetaceae. Three of the identified CSIs are uniquely shared by the genera Treponema, Spirochaeta, and Sphaerochaeta. One example of a CSI specific to these three genera, a 1 aa deletion in the $30 \mathrm{~S}$ ribosomal protein S13, a component of the protein translation complex, is shown in Figure 7A. Sequence information for 2 other CSIs specifically found in these three genera is provided in Table 5 and Supplemental Figures 14, 15. An additional 16 CSIs were uniquely shared by members of the genus Borrelia. One example of a CSI consisting of a 6 aa insertion in the glycolysis related protein, phosphofructokinase, that is specific to the members of the genus Borrelia is shown in Figure 7B. Fifteen other CSIs were also specifically found in members of the genus Borrelia and information for them is presented in Table 5 and Supplemental Figures 16-30.

\section{DISCUSSION}

The phylum Spirochaetes is currently distinguished from other bacteria on the basis of both branching in 16S rRNA sequence based phylogenies and the presence of the endoflagella that characterizes the phylum (Paster, 2011a; Euzéby, 2013). Apart from the presence of endoflagella, no reliable morphological, biochemical, or molecular characteristics are known that are specifically shared by all members of the phylum. Additionally, the phylum contains four divergent lineages, contained within a single class/order, that are demarcated largely on the basis of 16S rRNA sequence based phylogenies (Paster, 2011a). In this work, we have utilized comparative genomic techniques to identify large numbers of novel molecular signatures (CSIs) that are distinctive characteristics of either all members of the phylum Spirochaetes or for its different subgroups at multiple phylogenetic levels and which can be used to demarcate these groups in more definitive molecular terms. A summary diagram depicting the species distribution of the identified CSIs is shown in Figure 8.

The phylum Spirochaetes is rare in having a defining morphological characteristic, the endoflagella, which correlates to the clustering of the members of the phylum in $16 \mathrm{~S}$ rRNA phylogenetic trees (Ludwig and Klenk, 2001; Cavalier-Smith, 2002; Paster, 2011a). The endoflagella is a unique feature of the phylum and is thought to responsible for the great pathogenic and ecological diversity of its many members (Ren et al., 2003). Of the 38 CSIs we have identified in this study, one was uniquely shared by all 48 members of the phylum Spirochaetes and absent in every other sequenced group of bacteria. The identified CSI is located in the flagellar basal-body rod protein FlgC, a core component of the motor complex of the flagella (Macnab, 2003). This CSI provides a novel means to distinguish the members of the phylum from all

Table 2 | Conserved signature Indels that are specific for members of the family Spirochaetaceae.

\begin{tabular}{|c|c|c|c|c|c|}
\hline Protein name & $\begin{array}{l}\text { Gene } \\
\text { name }\end{array}$ & $\begin{array}{l}\text { GI } \\
\text { number }\end{array}$ & $\begin{array}{l}\text { Figure } \\
\text { number }\end{array}$ & $\begin{array}{l}\text { Indel } \\
\text { size }\end{array}$ & $\begin{array}{l}\text { Indel } \\
\text { position }\end{array}$ \\
\hline Phosphoribosylpyrophosphate synthetase & prsA & 496158147 & Figure 4 & 15 aa ins & $97-143$ \\
\hline Phosphoribosylpyrophosphate synthetase & prsA & 387827445 & Supplemental Figure 2 & 8 aa ins & $256-297$ \\
\hline Preprotein translocase & $\sec Y$ & 15639201 & Supplemental Figure 3 & 1 aa del & $340-373$ \\
\hline DNA mismatch repair protein MutL & mutL & 338706271 & Supplemental Figure 6 & 4 aa del & $494-520$ \\
\hline
\end{tabular}




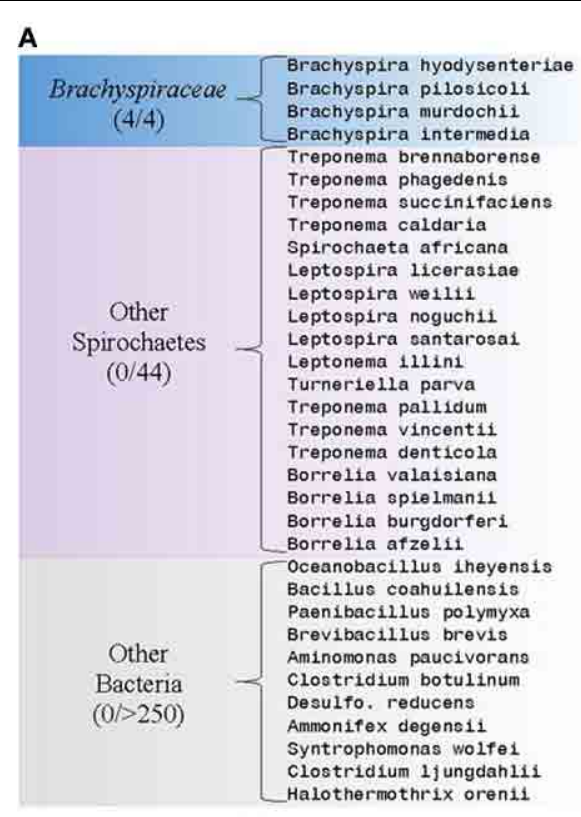

B

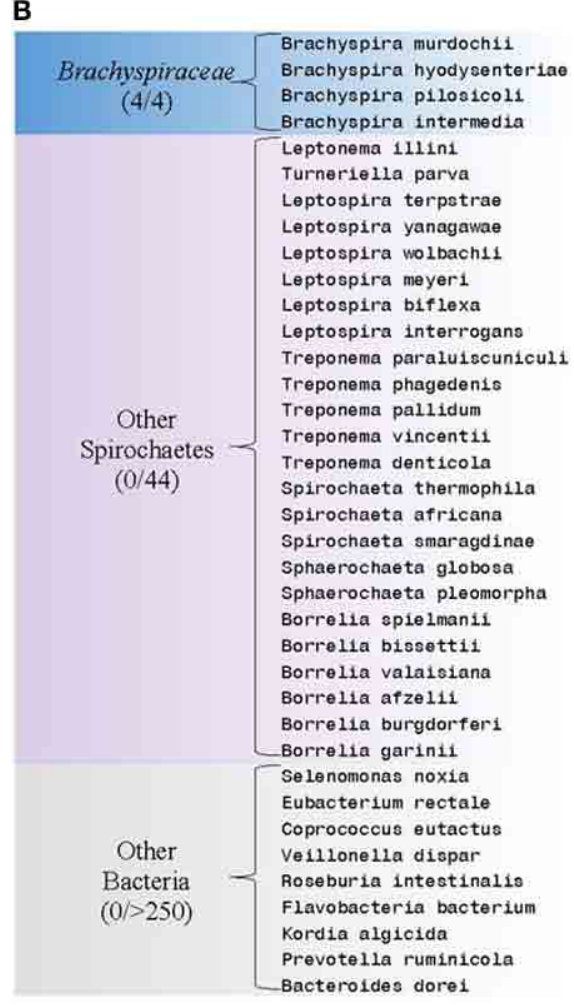

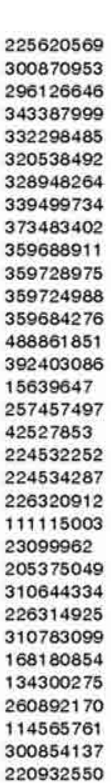

296127550

225621485

300871901

343385949

488857666

392404191

489061584

505584257

505590055

463323994

183220086

445566922

338706083

320535266

291059523

257457843

42527145

307717956

383791874

302340150

325970645

359351236

224534662

343127849

224532146

216263573

195941682

219685277

292669881

291525363

163814036

238019447

291535124

126663071

163753855

294675119

212692553

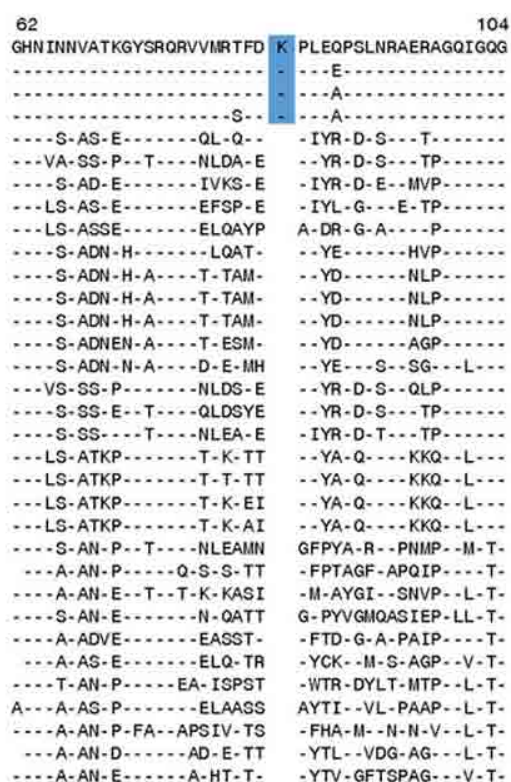

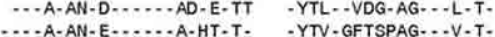

FIGURE 5 | Partial sequence alignments of (A) Flagellar hook-associated protein FlgK and (B) DNA polymerase $\mathrm{I}$, showing two CSIs that are specific for the family Brachyspiraceae, but not found in the sequence homologs of any other sequenced bacteria. Sequence homologs for flagellar hook-associated protein FlgK were not identified from members of the genus Sphaerochaeta. Sequence information for other Brachyspiraceae specific CSIs is presented in Supplemental Figures 7-10 and summarized in Table 3. other bacteria in molecular terms and provides another delimiting marker for the group in addition to the endoflagella. While the role of this CSI in the function or morphology of the Spirochaetes flagella is currently unknown, the unique presence of this CSI in a flagellar protein in all members of the phylum Spirochaetes suggests that it may be related to the unique flagella ultrastructure of the phylum. Earlier work has established that the CSIs are primarily located on surface loops of proteins which are important 
Table 3 | Conserved signature Indels that are specific for members of the family Brachyspiraceae.

\begin{tabular}{|c|c|c|c|c|c|}
\hline Protein name & $\begin{array}{l}\text { Gene } \\
\text { name }\end{array}$ & $\begin{array}{l}\text { GI } \\
\text { number }\end{array}$ & $\begin{array}{l}\text { Figure } \\
\text { number }\end{array}$ & $\begin{array}{l}\text { Indel } \\
\text { size }\end{array}$ & $\begin{array}{l}\text { Indel } \\
\text { position }\end{array}$ \\
\hline Flagellar hook-associated protein FlgK & $\mathrm{flgK}$ & 225620569 & Figure $5 \mathrm{~A}$ & 1 aa ins & $62-104$ \\
\hline Valyl-tRNA synthetase & valS & 300871449 & Supplemental Figure 7 & 1 aa ins & $225-263$ \\
\hline Valyl-tRNA synthetase & valS & 300871449 & Supplemental Figure 8 & 2 aa del & $660-703$ \\
\hline
\end{tabular}

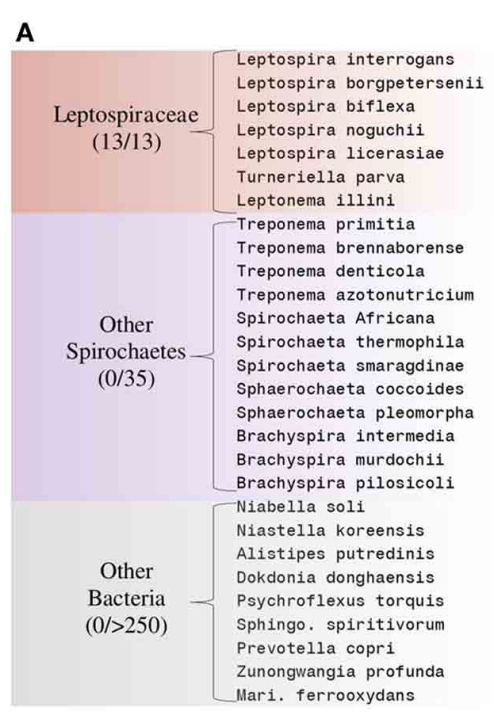

B

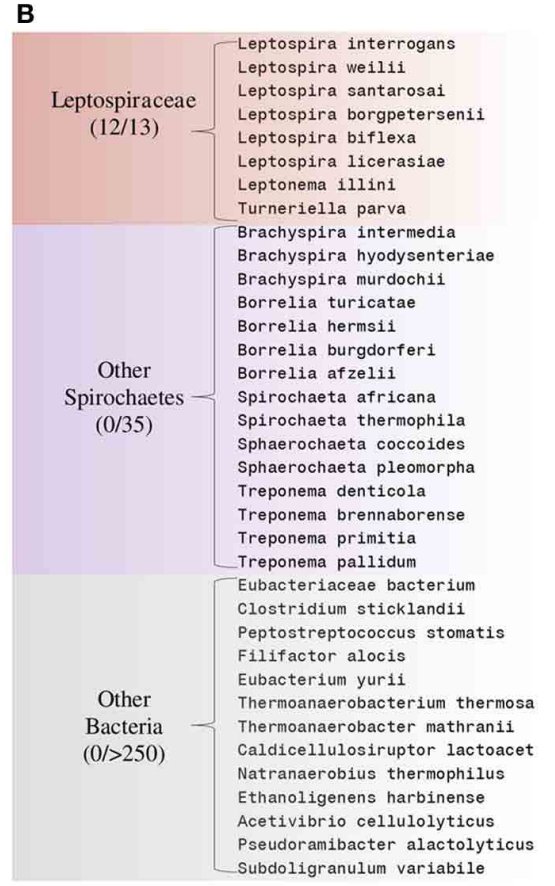

\begin{tabular}{|c|c|c|}
\hline & 36 & 10 \\
\hline 3214 & GDEIIVAVKDAQPAFGLKDS TGKKVHNK & AVQRAVVVRT \\
\hline 16327234 & 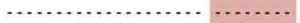 & n.......... \\
\hline 183221337 & ......E. & .... \\
\hline 359723222 & - & \\
\hline 359687079 & (.). & n........ \\
\hline 392404093 & -I -V $\cdots$ A-T- $-Y-I \cdots A-\cdots D-K-$ & $Q \cdots \cdots+\cdots$ \\
\hline 373876420 & 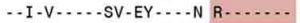 & $\cdots-k \cdots \cdots$ \\
\hline 333998879 & $\cdots I-V \cdots \cdots \cdot-$ L-TSTI $-K G$ & T.EK - ...... \\
\hline 2298903 & - I - V . . . . I I-TSTI-KG & SIEK--I -. \\
\hline 88746686 & $\cdots I-V \cdots \cdots, L-T S T I-K G$ & S-EK--IN \\
\hline 3996155 & - I I-V - . - - L-TSAI-KG & - -EK-...... \\
\hline 3789798 & $--V-V-\ldots-$ - I-NAP - -KG & $N-E \cdots-I \cdots$ \\
\hline 77718216 & $\cdots$ L-V-S- -E-L-DAP - -KG & $T+\ldots \ldots \ldots$. \\
\hline 302337487 & - - I-V - . - - - L-NGNI -KG & D- - K - I - \\
\hline 330837645 & $--V-V-\ldots \ldots$ L-NGAI-KG & D-LK-I - $\cdots$ \\
\hline 374316502 & - I -V - . - N-L-L-NGAI-KG & $D-M K--I \cdots$ \\
\hline 384210002 & - -V - CS-T-II-TCSIEKG & K-VK--I -. \\
\hline 296126875 & - V-VCS-T-II-TCSIEKG & $K-V K--I \cdots$ \\
\hline 300870637 & -V-VCS-T-II-TCSIEKG & $K-V K--I \cdots$ \\
\hline 373233633 & - -K-V-T-W.T-.-G-I-KG & $\cdots A K \cdots I \cdots$ \\
\hline 361061937 & $--K-V-T-\cdots-I--G-I-K G$ & - TK- - I - \\
\hline 167752395 & - -K-V-...S-S-S-SGDV-KG & . -sk -...... \\
\hline 86132554 & - -K-V-S-W-T-NGQV-KG & -.st....... \\
\hline 91216900 & -KVV-S--E-T-NGNI-KG & .-ST....... \\
\hline 227538708 & - -K-V-T-.S-L-SGNV-KG & s.sk....... \\
\hline 281422241 & $-V-V \ldots \ldots N V I-S S D-. K G$ & --SK-LI... \\
\hline 295135691 & $-K-V-S--E-T-N G N I-K G$ & ..ST...... \\
\hline 114778814 & $V \cdots \cdots E-I$ & \\
\hline
\end{tabular}

45656657
359728223
359683791
116331894
183220780
359686873
488860306
392404112
343385516
225620397
296126160
119953017
187918093
488734245
384206719
383791404
386347103
330837065
374317032
488766025
332297434
333999524
189026240
363892665
310658795
307243232
320120352
306820448
304316715
297544523
344996005
188586395
317133026
366164567
315924764
261366901
165

GACGPCSELYLDRGIEKGGPNCA TSGT 211

.

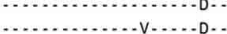

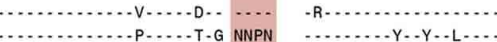

.

P

-

RA-.

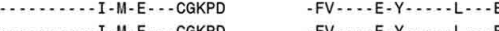

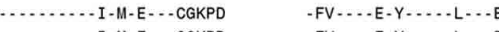

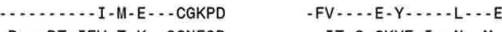

-P...DT-IFV-T-K-.CSNECD IT-S-GKYF-I - - N - M -

-P...DT-IFV-T-K-.CSVRCD IT-S-GKYF-I - -N- - M-

-P...DT-I-V-T-KS-CSLDCN IT-S-GKYF-I - -N- - M -

-P...DT-I-V-T-KI-CSINCN VT-S-GKYF-I - -N- - M -

-P...DT-IFF-T-VPPCSVSCR -..S. GKYV-I -D- II-

-P. DT- DFF-T-MPCSVSCR

C.S-GKYF-I - D. - ME

P...D-.IFF-TRRQTNNPDSR -.SSDG-YF-I - N - - M

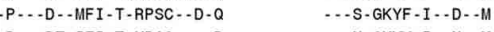

-P..-DT-IFI-T-KPAC...R R W-N-GKYV-I - N - - M -

-P..-DT-IFI-T-KRACSENCR N.-G-GKYI-I - -N- - M-

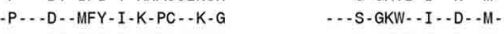

-P...DT-IFF-T-VPPCSVSCR A.S-GKYV-I -.D.-M-

-P......I-I...K-Y-CDDPN H............... T-

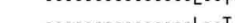

P.

P...... I-F-KEKY - CGCED

P..

-P.....I-I I...E-F-CGHKD

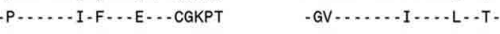

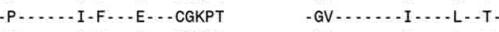

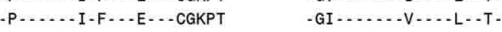

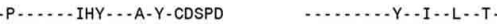

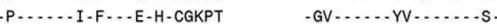

P...... I-Y Y - V R-CGKPD

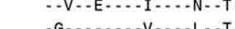

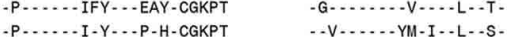

FIGURE 6 | Partial sequence alignments of (A) 50S Ribosomal protein L14 and (B) Alanyl-tRNA synthetase, showing two CSIs that are specific for the family Leptospiraceae, but not found in the sequence homologs of any other sequenced bacteria. Sequence information for other Leptospiraceae specific CSIs is presented in Supplemental Figures 11-13 and summarized in Table 4. 
Table 4 | Conserved signature Indels that are specific for members of the family Leptospiraceae.

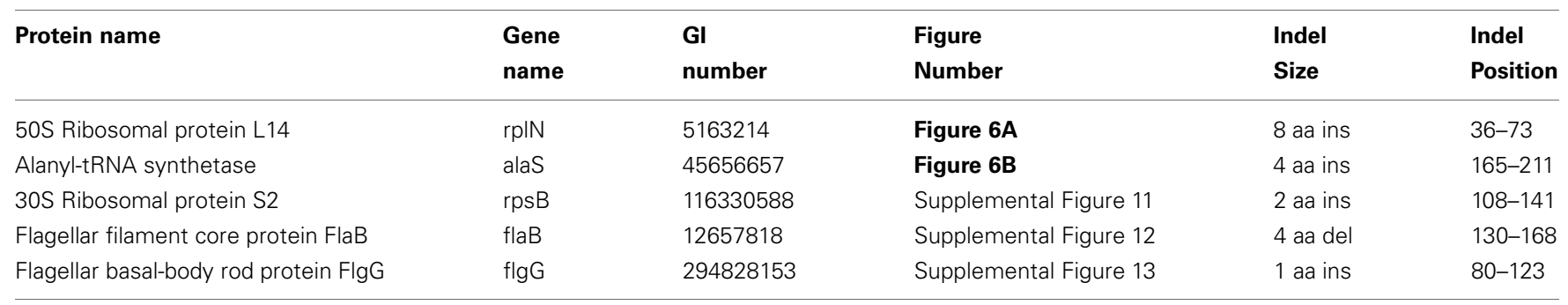

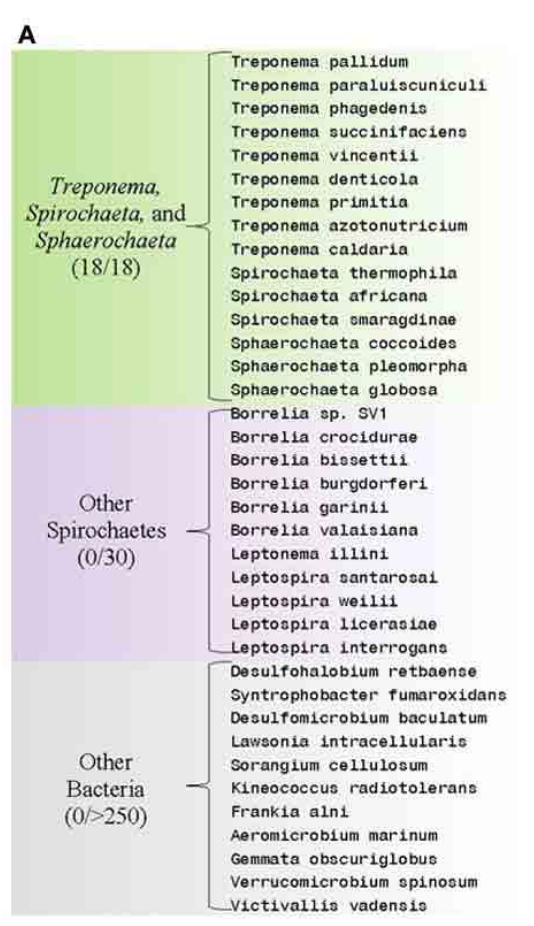

B

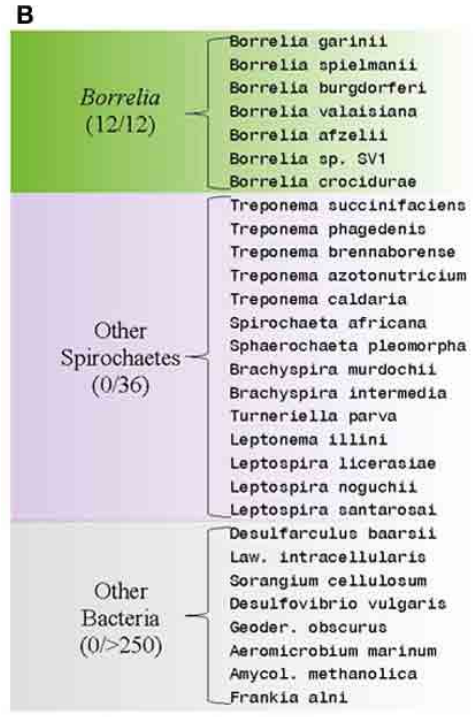

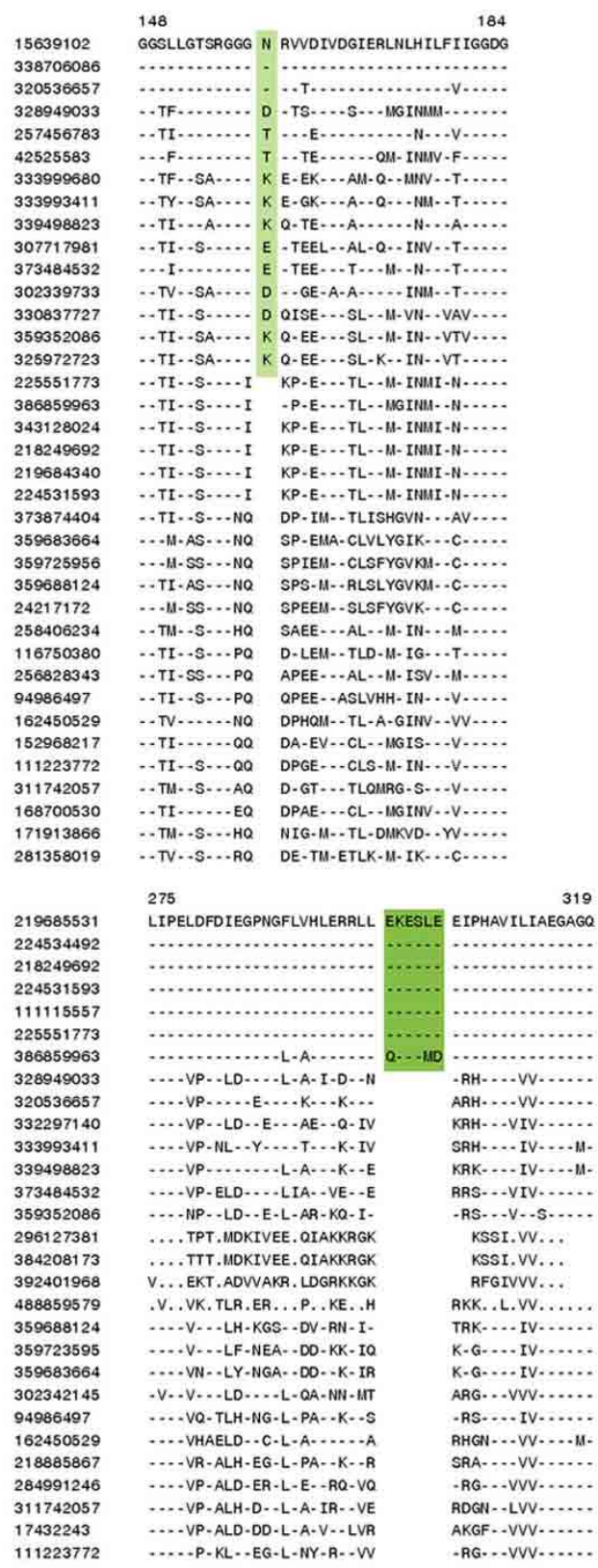

FIGURE 7 | (A) Partial sequence alignment of the protein 6-phosphofructokinase (pyrophosphate) containing a 1 amino acid insert in a conserved region that is specifically present in the species from the genera Treponema, Spirochaeta, and Sphaerochaeta, but not found in any other sequenced bacteria. (B) Partial sequence alignment of phosphofructokinase containing a 6 amino acid insert that is specific for the genera Borrelia. Sequence information for other CSIs showing similar specificities is provided in Table 5 and in Supplemental Figures 14-30. 
Table 5 | Conserved Signature Indels that are specific for groups within the family Spirochaetaceae.

\begin{tabular}{|c|c|c|c|c|c|c|}
\hline Protein name & $\begin{array}{l}\text { Gene } \\
\text { name }\end{array}$ & $\begin{array}{l}\text { GI } \\
\text { Number }\end{array}$ & $\begin{array}{l}\text { Figure } \\
\text { Number }\end{array}$ & Specificity & $\begin{array}{l}\text { Indel } \\
\text { size }\end{array}$ & $\begin{array}{l}\text { Indel } \\
\text { position }\end{array}$ \\
\hline 6-phosphofructokinase (pyrophosphate) & $\mathrm{pfp}$ & 15639102 & Figure 7A & $\begin{array}{l}\text { Treponema, Spirochaeta } \\
\text { and Sphaerochaeta }\end{array}$ & 1 aa ins & 148-184 \\
\hline Bifunctional Hpr kinase/phosphatase & hprk & 3322886 & Supplemental Figure 14 & $\begin{array}{l}\text { Treponema, Spirochaeta } \\
\text { and Sphaerochaeta }\end{array}$ & 1 aa ins & $183-221$ \\
\hline $30 \mathrm{~S}$ ribosomal protein $\mathrm{S} 13$ & rpsM & 302337499 & Supplemental Figure 15 & $\begin{array}{l}\text { Treponema, Spirochaeta } \\
\text { and Sphaerochaeta }\end{array}$ & 1 aa del & $1-39$ \\
\hline Phosphofructokinase & pfk & 219685531 & Figure 7B & Borrelia & 6 aa ins & 275-319 \\
\hline $50 S$ ribosomal protein $L 4$ & rplD & 224534698 & Supplemental Figure 16 & Borrelia & 1 aa ins & $103-136$ \\
\hline tRNA pseudouridine 55 synthase & truB & 203284699 & Supplemental Figure 17 & Borrelia & 2 aa ins & $143-178$ \\
\hline Translation elongation factor Tu & tuf & 203284386 & Supplemental Figure 18 & Borrelia & 1 aa del & 330-369 \\
\hline Histidyl-tRNA synthetase & hisS & 187918014 & Supplemental Figure 19 & Borrelia & 1 aa del & 273-301 \\
\hline Seryl-tRNA synthetase & sers & 187918098 & Supplemental Figure 20 & Borrelia & 1 aa del & $231-264$ \\
\hline Ribonuclease Z & $\mathrm{rnz}$ & 195941574 & Supplemental Figure 24 & Borrelia & 2 aa ins & $64-94$ \\
\hline Hypothetical protein BGAFAR04_0762 & - & 386859948 & Supplemental Figure 25 & Borrelia & 1 aa ins & $206-236$ \\
\hline Signal recognition particle, subunit FFH/SRP54 & - & 119953471 & Supplemental Figure 26 & Borrelia & 1 aa ins & $374-412$ \\
\hline Hypothetical protein BSV1_0075 & - & 15594416 & Supplemental Figure 27 & Borrelia & 1 aa del & $52-97$ \\
\hline Aspartyl/glutamyl-tRNA amidotransferase subunit $A$ & gat $A$ & 119953137 & Supplemental Figure 28 & Borrelia & 1 aa ins & $364-402$ \\
\hline Ribosomal RNA methyltransferase & $\mathrm{rlmE}$ & 203284234 & Supplemental Figure 29 & Borrelia & 1 aa ins & $15-48$ \\
\hline LysM domain/M23/M37 peptidase domain protein & - & 224534310 & Supplemental Figure 30 & Borrelia & 1 aa ins & $320-365$ \\
\hline
\end{tabular}

in protein-protein interactions (Akiva et al., 2008; Singh and Gupta, 2009; Gupta, 2010). Thus, the CSI identified in FlgC likely plays an important role in the cellular functions of the flagellar basal-body.

The phylum Spirochaetes contains 4 main lineages (viz. Spirochaetaceae, Brachyspiraceae, Leptospiraceae, and Brevinemataceae). These lineages have historically been distinguished from each other by their biochemical characteristics and their 16S rRNA gene sequences (Harwood and Canale-Parola, 1984; Paster et al., 1991; Paster, 2011a). In this study we have also identified 22 CSIs in a diverse range of proteins that are specific to each of the main sequenced lineages of the phylum Spirochaetes (viz. Spirochaetaceae, Brachyspiraceae, and Leptospiraceae), which serve to distinguish these lineages from themselves and all other bacteria. Seven of these identified CSIs were specific for the family Spirochaetaceae, 6 CSIs were identified that were specific for the family Brachyspiraceae, and 5 CSIs were identified that were specific to the family Leptospiraceae. Each of these lineages also branch distinctly and are separated by long branches in both $16 \mathrm{~S}$ rRNA based and concatenated protein based phylogenetic trees (Figures 1, 2). This molecular and phylogenetic evidence supports the current division of these lineages. However, the large number of CSIs discovered for each of these groups and their genetic distances suggests that these lineages may represent higher taxonomic divisions (viz. orders or classes) than currently recognized. It is noteworthy that two of the CSIs that are specific for the Brachyspiraceae family and one that is specific for the Leptospiraceae are again found in flagella-related proteins (viz. FlgK, FlgB, FlgG) indicating that there might be interesting differences in the structures and/or functions of flagella within the Spirochaete families.

The family Spirochaetaceae, which contains the genera Borrelia, Clevelandina, Cristispira, Diplocalyx, Hollandina, Pillotina, Sphaerochaeta, Spirochaeta, and Treponema, is the most diverse of the lineages within the phylum Spirochaetes (Paster, 2011b; Euzéby, 2013). The interrelationships between the genera within this family are not reliably resolved by $16 \mathrm{~S}$ rRNA sequence analysis (Paster, 2011b) (Figure 2). In this study we have identified 19 CSIs which serve to delineate at least certain relationships within the family Spirochaetaceae. Three of the CSIs identified are specifically found in members of the genera Sphaerochaeta, Spirochaeta, and Treponema and 16 additional CSIs were identified that are specifically found in members of the genus Borrelia. These CSIs suggest that the genera Sphaerochaeta, Spirochaeta, and Treponema shared a common ancestor distinct from the members of the genus Borrelia. In our concatenated protein phylogenetic tree, the genera Sphaerochaeta, Spirochaeta and Treponema formed a well-supported monophyletic clade, which was separated from the members of the genus Borrelia by a long branch, supporting the relationship delineated by these CSIs. Both of these two clades also exhibit considerable phylogenetic diversity. The clade consisting of genera Sphaerochaeta, Spirochaeta, and Treponema contains a number of distinct smaller subclades while the members of the genus Borrelia form two highly distinct clades in the phylogenetic trees. However, further work to identify molecular markers will be required to determine the significance of the branching of these subclades. The genus Cristispira has not had its genome sequenced, but it branches 


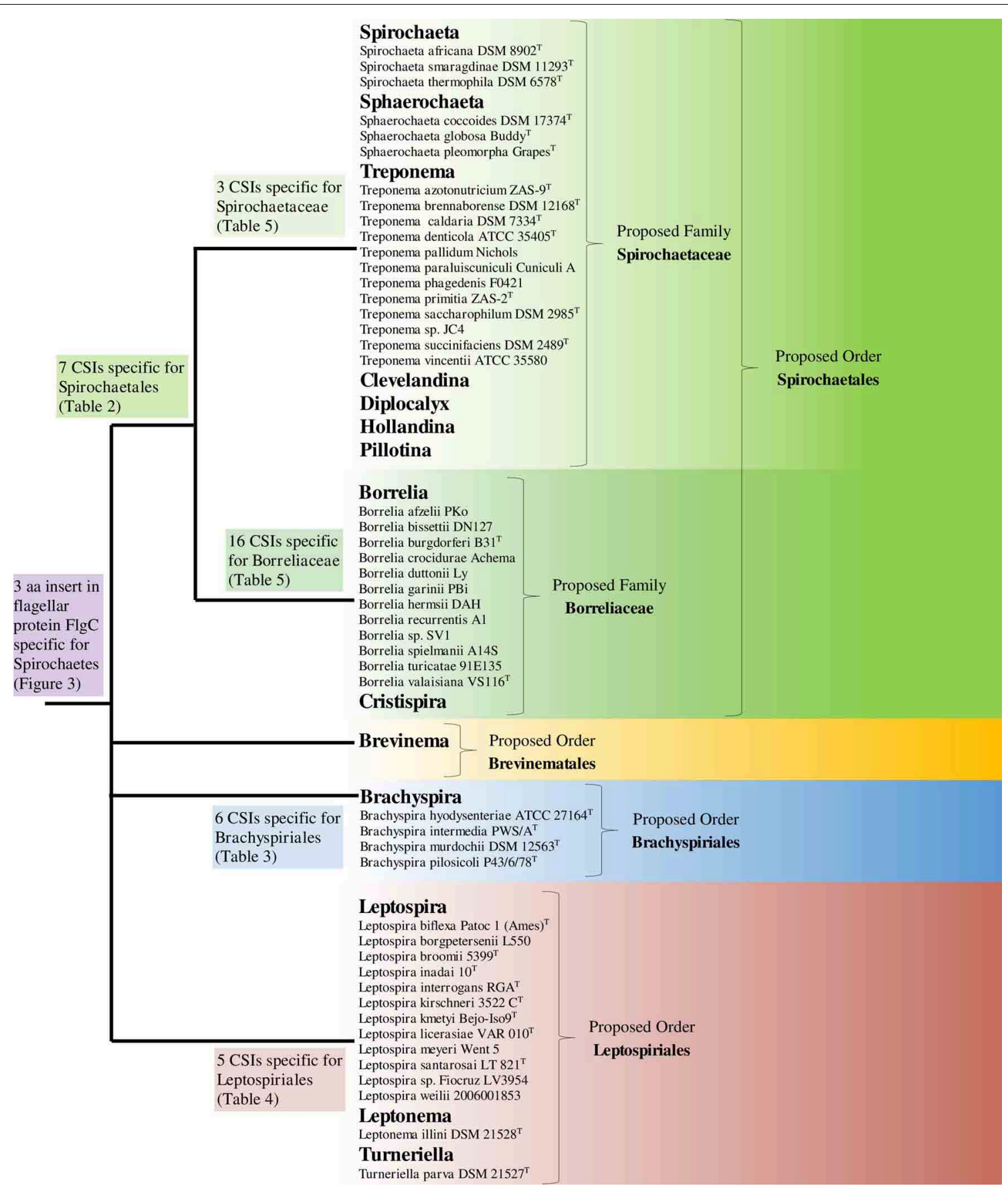

FIGURE 8 | A summary diagram depicting the distribution of identified CSIs and the proposed reclassification of the groups within the phylum Spirochaetes. A representative strain is listed for each genome sequenced species. The letter ${ }^{\top}$ refers to the type strain of the species.

with the members of the genus Borrelia reliably in 16S rRNA based phylogenetic trees suggesting that some, if not all, of the Borrelia specific CSIs identified in this study may also be found in Cristispira (Paster, 2011b) (Figure 2). The remaining members of the family Spirochaetaceae (viz. Clevelandina, Diplocalyx, Hollandina, and Pillotina) have been identified in the hindguts of termite and cockroaches but have yet to be isolated and grown in pure or mixed culture. The current placement of the identified members of Clevelandina, Diplocalyx, Hollandina, and Pillotina in distinct genera within the family Spirochaetaceae is ambiguous and based largely on analyses of morphological characteristics (Bermudes et al., 1988). No genome or 16S rRNA sequences are currently available from these genera for phylogenetic analysis. However, the observations presented in this report suggest that 
the family Spirochaetaceae contains at least two distinct monophyletic groups: one consisting of the genera Sphaerochaeta, Spirochaeta, and Treponema and another consisting of the genera Borrelia and Cristispira.

\section{TAXONOMIC IMPLICATIONS}

The results presented here show that the main lineages of the phylum Spirochaetes are evolutionarily distinct. The families Spirochaetaceae, Brachyspiraceae, and Leptospiraceae are distinguished from each other and all other bacteria by large numbers of identified CSIs in widely distributed proteins. Additionally, these three families branch distinctly in both 16S rRNA based and concatenated protein based phylogenetic trees. The results presented here also show that the family Spirochaetaceae consists of two distinct monophyletic groups. The distinctiveness of these groups is supported by both molecular evidence, in the form of the large numbers of discovered CSIs, and phylogenetic analyses. Additionally, both of these distinct groups exhibit a large amount of phylogenetic diversity which is currently not reflected in their taxonomy. The current taxonomic organization of the phylum Spirochaetes places all of the main lineages (viz. Spirochaetaceae, Brachyspiraceae, Leptospiraceae, and Brevinemataceae) into a single order. However, to adequately recognize both distinctiveness of the main lineages within the phylum Spirochaetes and the distinctiveness and diversity of the two main groups within the family Spirochaetaceae, the main lineages of the phylum Spirochaetes would have to have their taxonomic rank increased. To recognize the distinctiveness of both the main lineages within the phylum Spirochaetes and the two main groups within the family Spirochaetaceae we are proposing a taxonomic rearrangement of the phylum as follows: We propose that the family Leptospiraceae be transferred to the novel order Leptospiriales ord. nov. within the class Spirochaetia, the family Brachyspiraceae be transferred to the novel order Brachyspiriales ord. nov. within the class Spirochaetia, the family Brevinemataceae be transferred to the novel order Brevinematales ord. nov. within the class Spirochaetia, and that the genera Borrelia and Cristispira be transferred to the novel family Borreliaceae fam. nov. within the order Spirochaetales (Figure 8). The emended descriptions of the order Spirochaetales and the family Spirochaetaceae, as well as a description of the new taxonomic groups Leptospiriales ord. nov., Brachyspiriales ord. nov., Brevinematales ord. nov., and Borreliaceae fam. nov. are provided below.

\section{EMENDED DESCRIPTION OF THE ORDER Spirochaetales (BUCHANAN, 1917)}

The order contains two families, Spirochaetaceae and Borreliaceae, of which Spirochaetaceae is the type family. Organisms are helical or coccoid, $0.1-75 \mu \mathrm{m}$ in diameter and $3.5-250 \mu \mathrm{m}$ in length. Cells do not have hooked ends. Cells may possess flagella. Periplasmic flagella overlap in the central region of the cell. The diamino acid component of the peptidoglycan is Lornithine. Anaerobic, facultatively anaerobic, or microaerophilic. Organisms are Chemo-organotrophic and utilize carbohydrates or amino acids as carbon and energy sources. Both free living and host associated members. The G + C content of the DNA is 27-66 (mol\%). The type genus is Spirochaeta (Ehrenberg, 1835).
Organisms from this order are distinguished from all other Bacteria by the conserved signature indels (CSIs) described in this report in the following proteins: Alanyl-tRNA synthetase, Phosphoribosylpyrophosphate synthetase, SecY preprotein translocase, peptide chain release factor 2, DNA mismatch repair protein MutS, and DNA mismatch repair protein MutL.

\section{EMENDED DESCRIPTION OF THE FAMILY Spirochaetaceae (SWELLENGREBEL 1907 EMEND. ABT ET AL., 2012)}

The family contains seven genera, Clevelandina, Diplocalyx, Hollandina, Pillotina, Sphaerochaeta, Spirochaeta, and Treponema of which Spirochaeta is the type genus. Organisms are helical or coccoid, $0.1-75 \mu \mathrm{m}$ in diameter and $5-250 \mu \mathrm{m}$ in length. Cells do not have hooked ends. Cells may possess flagella. Periplasmic flagella overlap in the central region of the cell. Cells can be anaerobic or facultatively anaerobic. The diamino acid component of the peptidoglycan is L-ornithine. Organisms are chemoorganotrophic and utilize carbohydrates or amino acids as carbon and energy sources. Both free living and host associated members. The G + C content of the DNA is 36-66 (mol\%).

Organisms from this family are distinguished from all other bacteria by the CSIs described in this report in the following proteins: 6-phosphofructokinase (pyrophosphate), bifunctional Hpr kinase/phosphatase, and 30S ribosomal protein S13.

\section{DESCRIPTION OF Borreliaceae fam. nov.}

Borreliaceae (Bor.re'li.a'ce.ae. N.L. fem. n. Borrelia type genus of the family; -aceae ending to denote a family; M.L. fem. pl. n. Borreliaceae the Borrelia family).

The family contains two genera, Borrelia and Cristispira of which Borrelia is the type genus. Organisms are helical, $0.2-3 \mu \mathrm{m}$ in diameter and 3-180 $\mu \mathrm{m}$ in length. Cells do not have hooked ends. Periplasmic flagella overlap in the central region of the cell. Cells are motile, host-associated, and microaerophilic. The diamino acid component of the peptidoglycan is L-ornithine. Organisms are chemo-organotrophic and utilize carbohydrates or amino acids as carbon and energy sources. The $\mathrm{G}+\mathrm{C}$ content of the DNA is $27-32$ (mol\%).

Organisms from this family are distinguished from all other Bacteria by the CSIs described in this report in the following proteins: Phosphofructokinase, 50S ribosomal protein L4, tRNA pseudouridine 55 synthase, Translation elongation factor-Tu, Histidyl-tRNA synthetase, Seryl-tRNA synthetase, Spoiiij-associtated protein, Nicotinate phosphoribosyltransferase, Ribose 5-phosphate isomerase, Ribonuclease Z, Hypothetical protein BGAFAR04_0762, Signal recognition particle subunit FFH/SRP54, Hypothetical protein BSV1_0075, Aspartyl/glutamyl-tRNA amidotransferase subunit A, Ribosomal RNA methyltransferase, and a LysM domain/M23/M37 peptidase domain protein.

\section{DESCRIPTION OF Brachyspiriales ord. nov.}

Brachyspiriales (Bra.chy.spi.ra'les. N.L. fem. n. Brachyspira type genus of the order; suff. -ales ending to denote an order; N.L. fem. pl. n. Brachyspiriales the order of Brachyspira).

The order contains the type family Brachyspiraceae. Organisms are helical, $0.2-0.4 \mu \mathrm{m}$ in diameter and $2-11 \mu \mathrm{m}$ in length. Cell 
ends may be blunt or pointed and do not have hooked ends. Periplasmic flagella overlap in the central region of the cell. Cells are motile, host-associated, and obligately anaerobic and aerotolerant. The diamino acid component of the peptidoglycan is L-ornithine. Organisms are Chemo-organotrophic and utilize monosaccharides, disaccharides, the trisaccharide trehalose, and amino sugars as carbon and energy sources. The $\mathrm{G}+\mathrm{C}$ content of the DNA is $24-28(\mathrm{~mol} \%)$. The type genus is Brachyspira (Hovind-Hougen et al., 1982).

Organisms from this order are distinguished from all other bacteria by the CSIs described in this report in the following proteins: Flagellar hook-associated protein FlgK, DNA polymerase I, Valyl-tRNA synthetase, ATP-dependent protease La, and Glutamyl-tRNA amidotransferase subunit B. The description of the family Brachyspiraceae is the same as that of the order Brachyspiriales.

\section{DESCRIPTION OF Brevinematales ord. nov.}

Brevinematales (Bre.vi.ne.ma.ta'les. N.L. fem. n. Brevinema-atos type genus of the order; suff. -ales ending to denote an order; N.L. fem. pl. n. Brevinematales the order of Brevinema).

The description of the order is the same as the description of the type family, Brevinemataceae.

\section{DESCRIPTION OF Leptospiriales ord. nov.}

Leptospiriales (Lep.to.spi.ra'les. N.L. fem. n. Leptospira type genus of the order; suff. -ales ending to denote an order; N.L. fem. pl. n. Leptospiriales the order of Leptospira).

\section{REFERENCES}

Abt, B., Göker, M., Scheuner, C., Han, C., Lu, M., Misra, M., et al. (2013). Genome sequence of the thermophilic fresh-water bacterium Spirochaeta caldaria type strain (H1 ${ }^{T}$ ), reclassification of Spirochaeta caldaria and Spirochaeta stenostrepta in the genus Treponema as Treponema caldaria comb. nov., Treponema stenostrepta comb. nov., and Treponema zuelzerae comb. nov., and emendation of the genus Treponema. Stand. Genomic Sci. 8. doi: 10.4056/sigs.3096473. [Epub ahead of print].

Abt, B., Han, C., Scheuner, C., Lu, M., Lapidus, A., Nolan, M., et al. (2012). Complete genome sequence of the termite hindgut bacterium Spirochaeta coccoides type strain $\left(\mathrm{SPN}_{1}^{T}\right)$, reclassification in the genus Sphaerochaeta as Sphaerochaeta coccoides comb. nov. and emendations of the family Spirochaetaceae and the genus Sphaerochaeta. Stand. Genomic Sci. 6, 194. doi: 10.4056/sigs.2796069

Adeolu, M., and Gupta, R. S. (2013). Phylogenomics and molecular signatures for the order Neisseriales: proposal for division of the order Neisseriales into the emended family Neisseriaceae and Chromobacteriaceae fam. nov. Antonie Van Leeuwenhoek 104, 1-24. doi: 10.1007/s10482-013-9920-6

Adler, B., and de la Peña Moctezuma, A. (2010). Leptospira and leptospirosis. Vet. Microbiol. 140, 287-296. doi: 10.1016/j.vetmic.2009.03.012

Akiva, E., Itzhaki, Z., and Margalit, H. (2008). Built-in loops allow versatility in domain? Domain interactions: lessons from selfinteracting domains. Proc. Natl. Acad. Sci. U.S.A. 105, 13292. doi: 10.1073/pnas.0801207105

Altschul, S. F., Madden, T. L., Schäffer, A. A., Zhang, J., Zhang, Z., Miller, W., et al. (1997). Gapped, BLAST and PSI-BLAST: a new generation of protein database search programs. Nucleic Acids Res. 25, 3389-3402. doi: 10.1093/nar/25.17.3389

Anthony, N. E., Blackwell, J., Ahrens, W., Lovell, R., and Scobey, M. W. (2013). Intestinal spirochetosis: an Enigmatic disease. Dig. Dis. Sci. 58, 202-208. doi: 10.1007/s10620-0122305-2

Baldauf, S. L., and Palmer, J. D. (1993). Animals and fungi are each other's closest relatives: congruent evidence from multiple proteins. 11558-11562. doi: 10.1073/pnas.90. 24.11558 Proc. Natl. Acad. Sci. U.S.A. 90,

The order contains the type family Leptospiraceae. Organisms are helical, $0.1-0.3 \mu \mathrm{m}$ in diameter and $2-11 \mu \mathrm{m}$ in length. Cell have hooked ends. Periplasmic flagella do not overlap in the central region of the cell. Cells are motile. The diamino acid component of the peptidoglycan is $\alpha, \varepsilon$-diaminopimelic acid. Obligately aerobic or microaerophilic. Organisms are Chemo-organotrophic and long-chain fatty acids or long-chain fatty alcohols as carbon and energy sources. Both free living and host associated members. The $\mathrm{G}+\mathrm{C}$ content of the DNA is $33-55(\mathrm{~mol} \%)$. The type genus is Leptospira (Noguchi, 1917).

Organisms from this order are distinguished from all other Bacteria by the CSIs described in this report in the following proteins: 50S Ribosomal protein L14, 30S Ribosomal protein S2, Alanyl-tRNA synthetase, Flagellar basal-body rod protein FlgG, and Flagellar filament core protein FlaB. The description of the family Leptospiraceae is the same as that of the order Leptospiriales.

\section{ACKNOWLEDGMENTS}

This work was supported by a MRI-ORF Water Round research grant.

\section{SUPPLEMENTARY MATERIAL}

The Supplementary Material for this article can be found online at: http://www.frontiersin.org/Evolutionary_and_Genomic_Mic robiology/10.3389/fmicb.2013.00217/abstract

Bellgard, M. I., Wanchanthuek, P., La, T., Ryan, K., Moolhuijzen, P., Albertyn, Z., et al. (2009) Genome sequence of the pathogenic intestinal spirochete Brachyspira hyodysenteriae reveals adaptations to its lifestyle in the porcine large intestine. PloS ONE 4:e4641. doi 10.1371/journal.pone.0004641

Bermudes, D., Chase, D., and Margulis, L. (1988). Morphology as a basis for taxonomy of large Spirochetes symbiotic in wood-eating cockroaches and termites: Pillotina gen. nov., nom. rev.; Pillotina calotermitidis sp. nov., nom. rev.; Diplocalyx gen. nov., nom. rev.; Diplocalyx calotermitidis sp. nov., nom. rev. Hollandina gen. nov., nom. rev.; Hollandina pterotermitidis sp. nov., nom. rev.; and Clevelandina reticulitermitidis gen. nov., sp. nov. Int. J. Syst. Bacteriol. 38, 291-302. doi: 10.1099/00207713-38-3-291

Bhandari, V., Ahmod, N. Z., Shah, H. N., and Gupta, R. S. (2013). Molecular signatures for the Bacillus species: demarcation of the Bacillus subtilis and Bacillus cereus clades in molecular terms and proposal to limit the placement of new species into the genus Bacillus. Int. J. Syst. Evol. Microbiol. 63, 2712-2726. doi: 10.1099/ijs.0.048488-0
Buchanan, R. E. (1917). Studies in the nomenclature and classification of bacteria. II. The primary subdivisions of the Schizomycetes. J. Bacteriol. 2, 155-164.

Bulach, D. M., Zuerner, R. L., Wilson, P., Seemann, T., McGrath, A. Cullen, P. A., et al. (2006). Genome reduction in Leptospira borgpetersenii reflects limited transmission potential. Proc. Natl. Acad. Sci. U.S.A. 103, 14560-14565. doi: 10.1073/pnas.0603979103

Casjens, S. R., Fraser-Liggett, C. M., Mongodin, E. F., Qiu, W. G., Dunn, J. J., Luft, B. J., et al. (2011). Whole genome sequence of an unusual Borrelia burgdorferi sensu lato isolate. J. Bacteriol. 193, 1489-1490. doi: 10.1128/JB.01521-10

Castresana, J. (2000). Selection of conserved blocks from multiple alignments for their use in phylogenetic analysis. Mol. Biol. Evol. 17, 540-552. doi: 10.1093/oxfordjournals.molbev.a026334

Cavalier-Smith, T. (2002). The neomuran origin of archaebacteria, the negibacterial root of the universal tree and bacterial megaclassification. Int. J. Syst. Evol. Microbiol. 52, $7-76$.

Chaconas, G. (2005). Hairpin telomeres and genome plasticity in 
Borrelia: all mixed up in the end. Mol. Microbiol. 58, 625-635. doi: 10.1111/j.1365-2958.2005.04872.x

Chaconas, G., and Kobryn, K. (2010). Structure, function, and evolution of linear replicons in Borrelia. Annu. Rev. Microbiol. 64, 185-202. doi: 10.1146/annurev.micro.112408. 134037

Chou, L. F., Chen, Y. T., Lu, C. W., Ko, Y. C., Tang, C. Y., Pan, M. J., et al. (2012). Sequence of Leptospira santarosai serovar Shermani genome and prediction of virulence-associated genes. Gene. 511, 364-370. doi: 10.1016/j.gene. 2012.09.074

Ciccarelli, F. D., Doerks, T., Von Mering, C., Creevey, C. J., Snel, B., and Bork, P. (2006). Toward automatic reconstruction of a highly resolved tree of life. Science 311, 1283-1287. doi: 10.1126/science.1123061

Cutler, S. J. (2010). Relapsing fever: a forgotten disease revealed. J. Appl. Microbiol. 108, 1115-1122. doi: 10.1111/j.1365-2672.2009.04598.x

Dai, Q., Restrepo, B. I., Porcella, S. F., Raffel, S. J., Schwan, T. G., and Barbour, A. G. (2006). Antigenic variation by Borrelia hermsii occurs through recombination between extragenic repetitive elements on linear plasmids. Mol. Microbiol. 60, 1329-1343. doi: 10.1111/j.13652958.2006.05177.x

Dworkin, M. S., Schwan, T. G., and Anderson, D. E. Jr., and Borchardt, S. M. (2008). Tick-borne relapsing fever. Infect. Dis. Clin. North Am. 22, 449. doi: 10.1016/j.idc.2008. 03.006

Ehrenberg, C. G. (1835). "Dritter Beitrag zur Erkenntniss grosser Organisation in der Richtung des kleinsten Raumes," in Abhandlungen der Preussischen Akademie der Wissenschaften (Berlin) aus den Jahre 1833-1835, 143-336.

Elbir, H., Gimenez, G, Robert, C., Bergström, S., Cutler, S., Raoult, D., et al. (2012). Complete genome sequence of Borrelia crocidurae. J. Bacteriol. 194, 3723-3724. doi: 10.1128/JB.00118-12

Ellen, R. P., and Galimanas, V. B. (2005). Spirochetes at the forefront of periodontal infections. periodontology $2000 \quad 38,13-32$. doi: 10.1111/j.1600-0757.2005.00108.x

Euzéby, J. P. (2013). List of Prokaryotic names with Standing in Nomenclature. Available online at: www.bacterio.net

Fraser, C. M., Casjens, S., Huang, W. M., Sutton, G. G., Clayton, R., Lathigra, R., et al. (1997).
Genomic sequence of a Lyme disease spirochaete, Borrelia burgdorferi. Nature 390, 580-586. doi: $10.1038 / 37551$

Gao, B., and Gupta, R. S. (2012a). Microbial systematics in the post-genomics era. Antonie Van Leeuwenhoek 101, 45-54. doi: 10.1007/s10482-011-9663-1

Gao, B., and Gupta, R. S. (2012b). Phylogenetic framework and molecular signatures for the main clades of the phylum Actinobacteria. Microbiol. Mol. Biol. Rev. 76, 66-112. doi: 10.1128/MMBR.05011-11

Gerbase, A. C., Rowley, J. T., Heymann, D. H. L., Berkley, S. F. B., and Piot, P. (1998). Global prevalence and incidence estimates of selected curable STDs. Sex. Transm. Infect. 74, S12.

Glöckner, G., Lehmann, R., Romualdi, A., Pradella, S., Schulte-Spechtel, U., Schilhabel, M., et al. (2004). Comparative analysis of the Borrelia garinii genome. Nucleic Acids Res. 32, 6038-6046. doi: 10.1093/nar/gkh953

Gogarten, J. P., Doolittle, W. F., and Lawrence, J. G. (2002). Prokaryotic evolution in light of gene transfer. Mol. Biol. Evol. 19, 2226-2238. doi: 10.1093/oxfordjournals.molbev.a004046

Goodner, B., Hinkle, G., Gattung, S., Miller, N., Blanchard, M., Qurollo, B., et al. (2001). Genome sequence of the plant pathogen and biotechnology agent Agrobacterium tumefaciens C58. Science 294, 2323-2328. doi: $10.1126 /$ science. 1066803

Griffiths, E., and Gupta, R. S. (2004). Signature sequences in diverse proteins provide evidence for the late divergence of the order Aquificales. Int. Microbiol. 7, 41-52.

Gupta, R. S. (1998). Protein phylogenies and signature sequences: a reappraisal of evolutionary relationships among archaebacteria, eubacteria, and eukaryotes. Microbiol. Mol. Biol. Rev. 62, 1435.

Gupta, R. S. (2009). Protein signatures (molecular synapomorphies) that are distinctive characteristics of the major cyanobacterial clades. Int J. Syst. Evol. Microbiol. 59, 2510.

Gupta, R. S. (2010). Molecular signatures for the main phyla of photosynthetic bacteria and their subgroups. Photosyn. Res. 104, 357-372. doi: 10.1007/s11120-0109553-9

Gupta, R. S., Chander, P., and George, S. (2012). Phylogenetic framework and molecular signatures for the class Chloroflexi and its different clades; proposal for division of the class Chloroflexi class. nov. into the suborder Chloroflexineae subord. nov., consisting of the emended family Oscillochloridaceae and the family Chloroflexaceae fam. nov., and the suborder Roseiflexineae subord. nov., containing the family Roseiflexaceae fam. nov. Antonie Van Leeuwenhoek 103, 99-119. doi: 10.1007/s10482-012-9790-3

Gupta, R. S., Chen, W. J., Adeolu, M., and Chai, Y. (2013). Molecular signatures for the class Coriobacteriia and its different clades; Proposal for division of the class Coriobacteriia into the emended order Coriobacteriales, containing the emended family Coriobacteriaceae and Atopobiaceae fam. nov., and Eggerthellales ord. nov., containing the family Eggerthellaceae fam. nov. Int. J. Syst. Evol. Microbiol. doi: 10.1099/ijs.0. 048371-0. [Epub ahead of print].

Gupta, R. S., and Griffiths, E. (2002). Critical issues in bacterial phylogeny. Theor. Popul. Biol. 61, 423-434. doi: 10.1006/tpbi.2002.1589

Håfström, T., Jansson, D. S., and Segerman, B. (2011). Complete genome sequence of Brachyspira intermedia reveals unique genomic features in Brachyspira species and phage-mediated horizontal gene transfer. BMC Genomics 12:395. doi: 10.1186/1471-2164-12-395

Han, C., Gronow, S., Teshima, H., Lapidus, A., Nolan, M., Lucas, S., et al. (2011). Complete genome sequence of Treponema succinifaciens type strain $\left(6091^{T}\right)$. Stand. Genomic Sci. 4, 361. doi: 10.4056/sigs. 1984594

Harris, J. K., Kelley, S. T., Spiegelman, G. B., and Pace, N. R. (2003). The genetic core of the universal ancestor. Genome Res. 13, 407-412. doi: 10.1101/gr.652803

Harwood, C. S., and Canale-Parola, E. (1984). Ecology of spirochetes. Annu. Rev. Microbiol. 38, 161-192. doi: 10.1146/annurev.mi.38.100184. 001113

Homma, M., DeRosier, D. J., and Macnab, R. M. (1990). Flagellar hook and hook-associated proteins of Salmonella typhimurium and their relationship to other axia components of the flagellum. J. Mol. Biol. 213, 819-832. doi: 10.1016/S0022-2836(05)80266-9

Hovind-Hougen, K., Birch-Andersen, A., Hendrik-Nielsen, R., Orholm, M., Pedersen, J. O., Teglbaerg, P. S., et al. (1982). Intestinal spirochetosis: morphological characterization and cultivation of the spirochete Brachyspira aalborgi gen. nov., sp. nov. J. Clin. Microbiol. 6, 1127-1136.
Jeanmougin, F., Thompson, J. D., Gouy, M., Higgins, D. G., and Gibson, T. J. (1998). Multiple sequence alignment with Clustal, $\mathrm{X}$. Trends Biochem. Sci. 23, 403. doi: 10.1016/S0968-0004(98)01285-7

Jones, D. T., Taylor, W. R., and Thornton, J. M. (1992). The rapid generation of mutation data matrices from protein sequences. Comput. Appl. Biosci. 8, 275-282.

Kobryn, K. (2007). "The linear hairpin replicons of Borrelia burgdorferi," in Microbial Linear Plasmids, eds F. Meinhardt, and R. Klassen (Heidelberg: Springer), 117-140.

Lescot, M., Audic, S., Robert, C., Nguyen, T. T., Blanc, G., Cutler, S. J., et al. (2008). The genome of Borrelia recurrentis, the agent of deadly louse-borne relapsing fever, is a degraded subset of tick-borne Borrelia duttonii. PLoS Genet. 4:e1000185. doi: 10.1371/journal.pgen.1000185

Li, C., Wolgemuth, C. W., Marko, M., Morgan, D. G., and Charon, N. W. (2008). Genetic analysis of spirochete flagellin proteins and their involvement in motility, filament assembly, and flagellar morphology. J. Bacteriol. 190, 5607-5615. doi: 10.1128/JB.00319-08

Lin, C., den Bakker, H. C., Suzuki, H., Lefébure, T., Ponnala, L., Sun, Q., et al. (2013). Complete genome sequence of the porcine strain Brachyspira pilosicoli $\mathrm{P} 43 / 6 / 78^{T}$. Genome Announc. 1. doi: 10.1128/ genomeA.00215-12. [Epub ahead of print].

Ludwig, W., and Klenk, H. P. (2001). "Overview: a phylogenetic backbone and taxonomic framework for prokaryotic systematics," in Bergey's Manual of Systematic Bacteriology, ed G. M. Garrity (New York, NY: Springer), 49-65.

Macnab, R. M. (2003). How bacteria assemble flagella. Annu. Rev. Microbiol. 57, 77-100. doi: 10.1146/ annurev.micro.57.030502.090832

Mavromatis, K., Yasawong, M., Chertkov, O., Lapidus, A., Lucas, S., Nolan, M., et al. (2010). Complete genome sequence of Spirochaeta smaragdinae type strain (SEBR $4228^{T}$ ). Stand. Genomic Sci. 3, 136. doi: 10.4056/sigs.1143106

Nau, R., Christen, H. J., and Eiffert, H. (2009). Lyme disease: ?current state of knowledge. Dtsch. Arztebl. Int. 106, 72. doi: 10.3238/arztebl.2009.0072

NCBI. (2013). NCBI Genome Database. Available online at: http://www. ncbi.nlm.nih.gov/genome/

Noguchi, H. (1917). Spirochaeta icterohaemorrhagiae in American wild 
rats and its relation to the Japanese and European strains. J. Exp. Med. 25, 755-763.

Olsen, I., Paster, B. J., and Dewhirst, F. E. (2000). Taxonomy of spirochetes. Anaerobe 6, 39-57. doi: 10.1006/anae.1999.0319

Paster, B. J. (2011a). "Phylum XV. Spirochaetes Garrity and Holt (2001)," in Bergey's Manual of Systematic Bacteriology, eds D. J. Brenner, N. R. Krieg, G. M. Garrity, and J. T. Staley (New York, NY: Springer), 471.

Paster, B. J. (2011b). "Family I. Spirochaetaceae Swellengrebel 1907, 581AL," in Bergey's Manual of Systematic Bacteriology, eds D. J. Brenner, N. R. Krieg, G. M. Garrity, and J. T. Staley (New York, NY: Springer), 473-531.

Paster, B. J., and Dewhirst, F. E. (2000). Phylogenetic foundation of spirochetes. J. Mol. Microbiol. Biotechnol. 2, 341-344.

Paster, B. J., Dewhirst, F. E., Weisburg, W. G., Tordoff, L. A., Fraser, G. J., Hespell, R. B., et al. (1991). Phylogenetic analysis of the spirochetes. J. Bacteriol. 173, 6101-6109.

Pati, A., Sikorski, J., Gronow, S., Munk, C., Lapidus, A., Copeland, A., et al. (2010). Complete genome sequence of Brachyspira murdochii type strain $\left(56-150^{T}\right)$. Stand. Genomic Sci. 2, 260.

Picardeau, M., Bulach, D. M., Bouchier, C., Zuerner, R. L., Zidane, N., Wilson, P. J., et al. (2008). Genome sequence of the saprophyte Leptospira biflexa provides insights into the evolution of Leptospira and the pathogenesis of leptospirosis. PloS ONE 3:e1607. doi: 10.1371/ journal.pone.0001607

Quast, C., Pruesse, E., Yilmaz, P., Gerken, J., Schweer, T., Yarza, P., et al. (2013). The, SILVA ribosomal, RNA gene database project: improved data processing and web-based tools. Nucleic Acids Res. 41, D590-D596. doi: 10.1093/nar/gks1219

Ren, S. X., Fu, G., Jiang, X. G., Zeng, R., Miao, Y. G., Xu, H., et al. (2003). Unique physiological and pathogenic features of Leptospira interrogans revealed by whole-genome sequencing. Nature 422, 888-893. doi: 10.1038/ nature 01597

Rokas, A., and Holland, P. W. H. (2000). Rare genomic changes as a tool for phylogenetics. Trends Ecol. Evol. 15, 454-459. doi: 10.1016/S0169-5347(00)01967-4

Rokas, A., Williams, B. L., King, N., and Carroll, S. B. (2003). Genome-scale approaches to resolving incongruence in molecular phylogenies. Nature 425, 798-804. doi: 10.1038 /nature02053

Schutzer, S. E., Fraser-Liggett, C. M., Qiu, W. G., Kraiczy, P., Mongodin, E. F., Dunn, J. J., et al. (2012). Whole-genome sequences of Borrelia bissettii, Borrelia valaisiana, and Borrelia spielmanii. J. Bacteriol. 194, 545-546. doi: 10.1128/JB.06263-11

Seshadri, R., Myers, G. S. A., Tettelin, H., Eisen, J. A., Heidelberg, J. F., Dodson, R. J., et al. (2004). Comparison of the genome of the oral pathogen Treponema denticola with other spirochete genomes. Proc. Natl. Acad. Sci. U.S.A. 101, 5646-5651. doi: 10.1073/pnas.0307639101

Singh, B., and Gupta, R. S. (2009). Conserved inserts in the Hsp60 (GroEL) and Hsp70 (DnaK) proteins are essential for cellular growth. Mol. Genet. Genomics 281, 361-373. doi: 10.1007/s00438-008-0417-3

Smajs, D., Norris, S. J., and Weinstock, G. M. (2012). Genetic diversity in Treponema pallidum: implications for pathogenesis, evolution and molecular diagnostics of syphilis and yaws. Infect. Genet. Evol. 12, 191-202. doi 10.1016/j.meegid.2011.12.001

Smajs, D., Zobaníková, M., Strouhal, M., Cjková, D., Dugan-Rocha, S., Pospísilová, P., et al. (2011). Complete genome sequence of Treponema paraluiscuniculi, strain Cuniculi A: the loss of infectivity to humans is associated with genome decay. PLoS ONE 6:e20415. doi 10.1371/journal.pone.0020415

Tamura, K., Peterson, D., Peterson, N. Stecher, G., Nei, M., and Kumar, S (2011). MEGA5: molecular evolutionary genetics analysis using maximum likelihood, evolutionary distance, and maximum parsimony methods. Mol. Biol. Evol. 28, 2731-2739. doi: 10.1093/molbev/ msr 121

Tavaré, S. (1986). "Some probabilistic and statistical problems in the analysis of, DNA sequences," in Lectures on Mathematics in the Life Sciences, ed R. M. Miura (Providence, RI American Mathematical Society) 57-86.

Visser, M. B., and Ellen, R. P. (2011). New insights into the emerging role of oral spirochaetes in periodontal disease. Clin. Microbiol. Infect. 17, 502-512. doi: 10.1111/j.14690691.2011.03460.x

Whelan, S., and Goldman, N. (2001) A general empirical model of protein evolution derived from multiple protein families using a maximum-likelihood approach. Mol. Biol. Evol. 18, 691-699. doi: 10.1093/oxfordjournals.molbev. a003851

Wu, D., Hugenholtz, P., Mavromatis, K., Pukall, R., Dalin, E., Ivanova, N. N., et al. (2009). A phylogeny-driven genomic encyclopaedia of
Bacteria and Archaea. Nature 462, 1056-1060. doi: 10.1038/ nature 08656

Zhong, J., and Barbour, A. G. (2004). Cross species hybridization of a Borrelia burgdorferi DNA array reveals infection and culture associated genes of the unsequenced genome of the relapsing fever agent Borrelia hermsii. Mol. Microbiol. 51, 729-748. doi: 10.1046/j.13652958.2003.03849.x

Conflict of Interest Statement: The authors declare that the research was conducted in the absence of any commercial or financial relationships that could be construed as a potential conflict of interest.

Received: 17 June 2013; paper pending published: 04 July 2013; accepted: 11 July 2013; published online: 30 July 2013.

Citation: Gupta RS, Mahmood S and Adeolu M (2013) A phylogenomic and molecular signature based approach for characterization of the phylum Spirochaetes and its major clades: proposal for a taxonomic revision of the phylum. Front. Microbiol. 4:217. doi: 10.3389/fmicb.2013.00217

This article was submitted to Frontiers in Evolutionary and Genomic Microbiology, a specialty of Frontiers in Microbiology.

Copyright (c) 2013 Gupta, Mahmood and Adeolu. This is an open-access article distributed under the terms of the Creative Commons Attribution License (CC BY). The use, distribution or reproduction in other forums is permitted, provided the original author(s) or licensor are credited and that the original publication in this journal is cited, in accordance with accepted academic practice. No use, distribution or reproduction is permitted which does not comply with these terms. 